\title{
MASTER
}

\section{STUDY OF ELECTRIC FIELD AND ION EFFECTS ON HVDC LINES}

\author{
Department of Energy \\ Contract No. DE-AC02-80RA50153 \\ (B\&R Number AK05-2000) \\ Technical Progress Report \#1 \\ January 1 - June 30, 1980 \\ Prepared by \\ GENERAL ELECTRIC COMPANY \\ 100 Woodlawn Avenue \\ Pittsfield, Massachusetts 01201 \\ Principal Investigators \\ Michael G. Comber \\ Gary B. Johnson
}

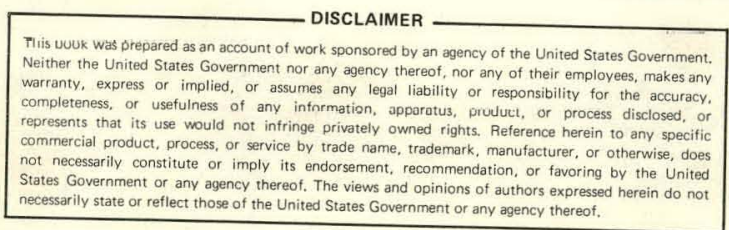

Prepared for

Department of Energy

Washington, DC 20545 


\section{DISCLAIMER}

This report was prepared as an account of work sponsored by an agency of the United States Government. Neither the United States Government nor any agency Thereof, nor any of their employees, makes any warranty, express or implied, or assumes any legal liability or responsibility for the accuracy, completeness, or usefulness of any information, apparatus, product, or process disclosed, or represents that its use would not infringe privately owned rights. Reference herein to any specific commercial product, process, or service by trade name, trademark, manufacturer, or otherwise does not necessarily constitute or imply its endorsement, recommendation, or favoring by the United States Government or any agency thereof. The views and opinions of authors expressed herein do not necessarily state or reflect those of the United States Government or any agency thereof. 


\section{DISCLAIMER}

Portions of this document may be illegible in electronic image products. Images are produced from the best available original document. 
Section 1

INTRODUCTION

This DOE-sponsored program is a 4-year research program primarily concerned with electric field and ion effects of hudc transmission lines. It parallels, in period of performance, an EPRI sponsored program (RP 1282-2) which is primarily concerned with conductor performance (audible noise, radio and television interference) and insulation performance. Various hudc facilities exist at Project UHV for conducting these programs. Some of the facilities were installed under a previous DOE-sponsored program (Contract \#EC-77-C-015059). These include an ac-dc converter station which can provide bipolar voltages up to $\pm 750 \mathrm{kV}$ or monopolar voltages up to $1500 \mathrm{kV}$, a $160 \mathrm{~m}$ bipolar overhead test line, and a bipolar conductor test bay. Additiona] facilities which have subsequently been installed under an. EPRI-sponsored program (RP 1282-1) include a 0-1500 kV hvdc cascade rectifier set, a $500 \mathrm{~m}$ bipolar test line, and a second ac-dc converter station capable of providing bipolar voltages up to $\pm 375 \mathrm{kV}$ or monopolar voltages up to $750 \mathrm{kV}$. In addition, other facilities previously used in ac research progralls are avallable for the dc programs: These include a conductor test cage for monopolar studies, and indoor facilities for small scale tests up to $\pm 150 \mathrm{kV}$.

The installation of the latest additions to the facilities was completed during the first half of the report period. Technical progress since then has been hampered by equipment failures and other operational problems associated with the hvdc generating facilities. Limited amounts of testing have been accomplished on both the $500 \mathrm{~m}$ line ("main test 1 ine") and the $160 \mathrm{~m}$ line ("short test line"). Many of the subject areas to be covered in this research program are only now getting under way because of the delays caused by the equipment problems. 
Section 2

RESEARCH TASKS

The program is divided into two main research tasks:

Task 1: Study of Electric Field and Ion Effects of Bipolar Hvdc Line Configurations with Voltages up to $\pm 1500 \mathrm{kV}$

The main dc line will be primarily used for this work. During the 4-year program several different line geometries will be studied. The first configuration is now under test. This consists of $6-5.59 \mathrm{~cm}$ conductors per pole, with pole spacing variable between $17 \mathrm{~m}$ and $32 \mathrm{~m}$. During energization of the line, electric field and ion current at 16 different ground locations are recorded together with other parameters influencing the line performance (e.g. line voltāge and weather parameters).

Task 1 includes a number of subtasks related to electric field and ion effects. Several of these are essentially a continuation of studies carried out under a previous DOE contract on dc field and ion effects (Contract \#EC-77-C-01-5059). The subtasks are:

1.1 Continued development of techniques for measuring such quantities as ion mobility, space charge density and space potential.

1.2 Investigation of the effect of charged aerosols (fine particles in the air).

1.3 Study of the human perception of electric field and ion effects, with the particular objective of determining whether perceived sensations are related to the presence of the electric field or the flow of ions.

1.4 Development of techniques for monitoring the exposure of personnel to de fields and ions.

i.5 Investigation of shielding methods to reduce the electric field and ion current at ground level.

1.6 Investigation of the magnitude and effect of corona current from objects such as trees and vegetation, poles, towers, guy wires and others which may be close to a hvdc transmission line.

1.7 Investigation of voltages and currents which could be induced in parallel wires, such as low voltage distribution lines, close to a hudc transmission line. 
1.8 Environmental analysis of hvdc lines with voltage in the range $250 \mathrm{kV}$ to $600 \mathrm{kV}$ (the short test line would be used for this subtask which will include measurements of electric fields and ion currents at ground, corona loss, audible noise and radio interference).

Task 2: Study of the Space Charge Generation Characteristics of Different Types of Conductors for Hidc Tranismission

For this task, both the bipolar conductor test bay and the monopolar conductor test cage will be used to investigate the performance of relatively small lengths of conductor or conductor bundle. Many aspects of the dc corona/ion current/field relationship, which are presently not well known and which are difficult to investigate on the large scale of the test line, can be more conveniently studied on the smaller scale of the test bay or test cage. These facilities also offer a more convenient means of comparing the performances of different conductors or conductor configurations since the time for changing out conductors is quite small (compared to that required for the 1 ine.). 
Section 3

TECHNICAL PROGRAM SUMMARY

Task 1: Study of Electric Fields and Ion Effects of Bipolar Hvdc Line Configurations

The main test line will be used for investigations above $\pm 600 \mathrm{kV}$ while the short test line will be used for voltages up to $\pm 600 \mathrm{kV}$. The 3-phase test line formerly used for an ac corona research program was converted to a bipolar dc test line (the main test line). The short test line was originally constructed as part of a former DOE program on field and ion effects. In order to be able to energize these two test lines independently, new hudc generating facilities were installed. A description of the new facilities is given in Appendix A. This Appendix also describes some of the operational problems experienced with the hvdc generating equipment which has caused a delay in several of the research activities.

During the report period, the main test line was instrumented for the measurement. of ground level electric fields and ion currents, audible noise, radio interference, corona loss, wind velocities at ground level and at conductor height, and atmospheric particle count. This equipment was installed under EPRI RP 1282 but will be used to obtain data for both the DOE and the EPRI programs. IIn a particular test period, measurements of many parameters will be made simultaneously. It is generally more convenient to report the analysis of all parameters for a given test period in one document; consequent $1 y$, analyses of the main test line data will. generally be reported in both DOE and EPRI technical progress reports].: The main 7 ine has been energized, on a somewhat sporadic basis due to hvdc equipment malfunctions, at voltages between \pm 750 $\mathrm{kV}$ and $\pm 1200 \mathrm{kV}$. During the first half of the reporting period, the line was energized for approximately $15 \mathrm{~h}$ at pole spacings of $24.5 \mathrm{~m}$ (the nominal spacing selected for the present configuration of $6-5.59 \mathrm{~cm}$ conductors per pole) and $17 \mathrm{~m}$. Ground level electric field and ion current measurements conducted during this period are reported in Appendix B. A field measuring system based around a Monroe Inc. Model 171 multichannel field meter, and an ion current measuring system of Project UHV design are used for these measurements. Sensors are located at 16 different locations, 13 of which are along a midspan lateral, and 3 at points longitudinally to the 1 ine. The systems allow "real-time" measurement of electric field and ion current profiles. 
During the second half of the report period, the main line was energized for longer periods of time at $24.5 \mathrm{~m}$ pole spacing. A preliminary analysis of the data collected during this period has been performed. Figures 3-1 and 3-2 show the results of the analysis at three test voltages. Each point on these figures represents the median electric field or ion current density at the indicated measuring location and voltage level. No attempt was made in this preliminary analysis to categorize the data according to climatic conditions such as wind speed or relative humidity. The number of records of data used in the analysis were as follows:

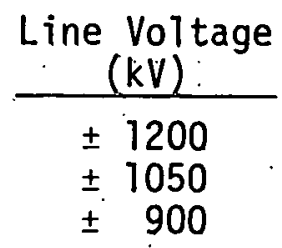

\begin{tabular}{c} 
No. of Records \\
\hline 3317 \\
3309 \\
530
\end{tabular}

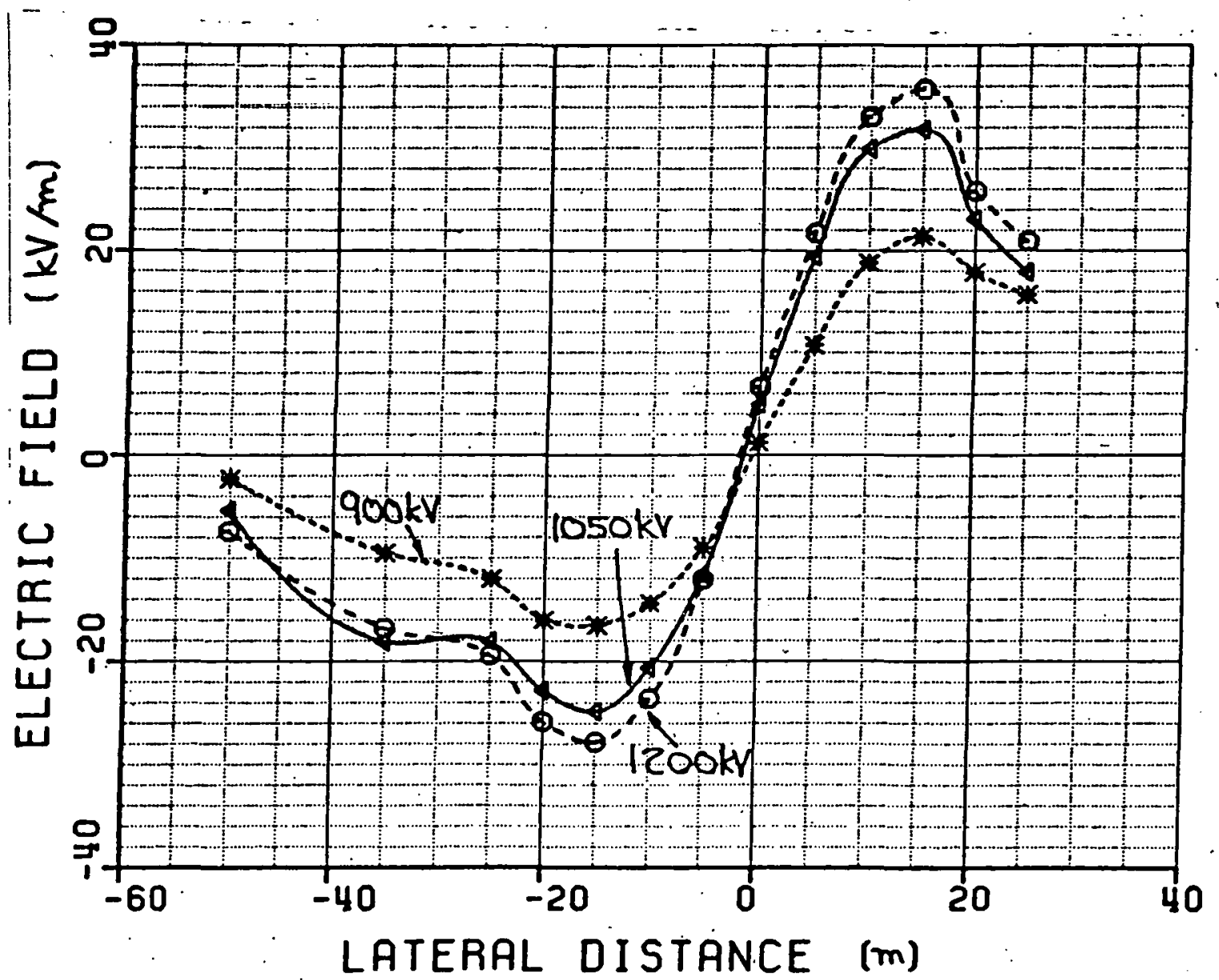

Figure 3-1. Lateral Profiles of Median Electric Field at Ground Level 


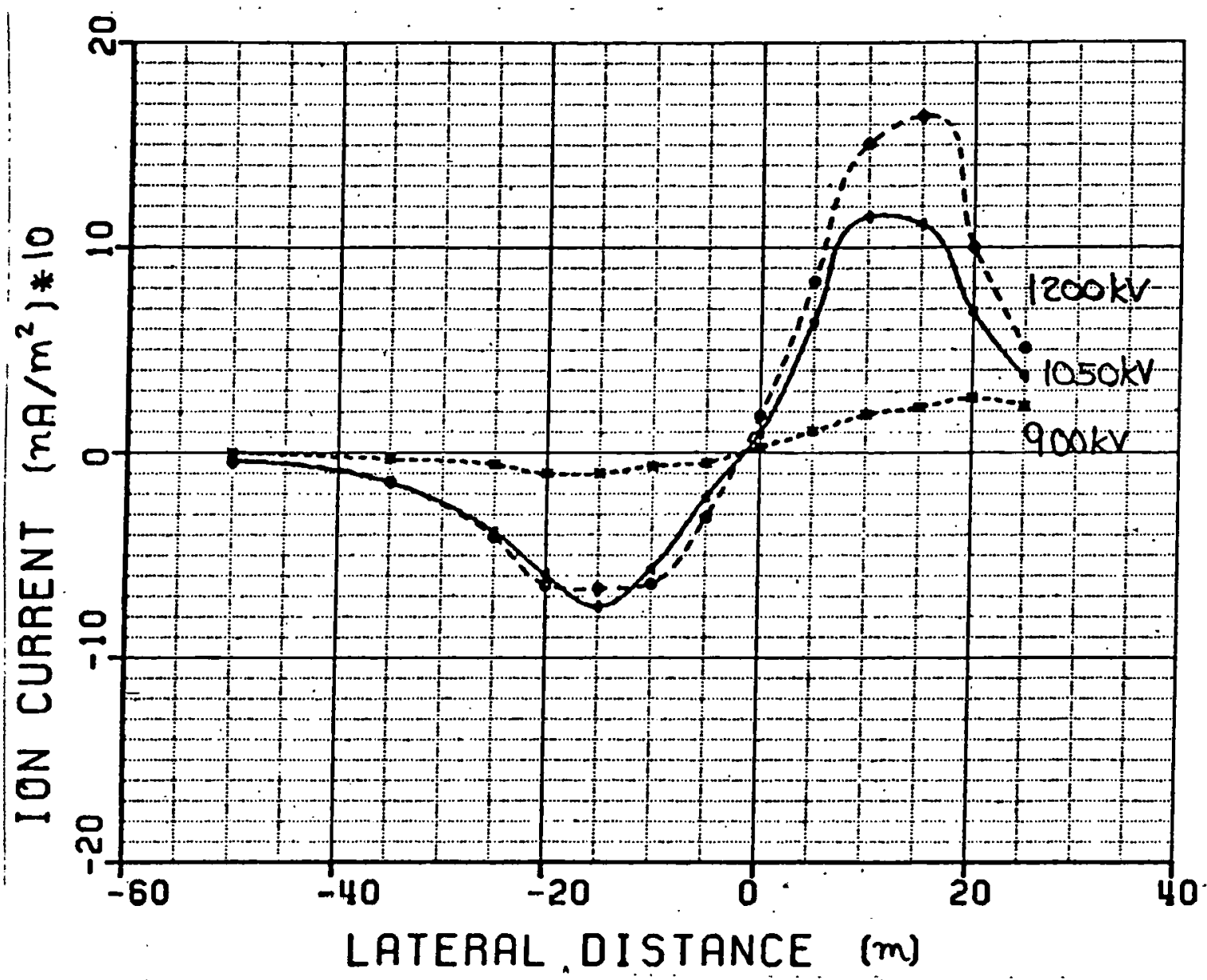

Figure 3-2. Lateral profiles of median ion current density at ground level.

(A11. data channels are sampled once each minute by a computer based data acquisition system, the resulting record of data being stored for later analysis).

Towards the end of the report period, the main line pole spacing was changed to $17 \mathrm{~m}$ in preparation for an extended period of testing. In order to investigate the effect of line geometry on the line performance, it is planned to periodically, on a routine basis, to change the pole spacing. Three pole spacings have been selected for the present conductor configuration, $17 \mathrm{~m}$, $24.5 \mathrm{~m}$, and $32 \mathrm{~m}$. In addition, on several occasions at each pole spacing, the 1 ine height at midspan will be varied over a relatively short period of time to determine the influence of this element of the line geometry (both pole spacing changes and line height changes can be accomplished with the line energized). 
At the end of the report period, the short $l$ ine was being reconstructed to provide the capability of varying conductor height and pole spacing (as constructed under the previous DOE contract it did not have this provision). Unlike the main line, however, spacing and height changes on the short line will have to be made with the line de-energized. In order to accomplish this reconstruction, the existing 1 ine, consisting of 4-3.05 cm conductors per pole, . had to be dismantled. Advantage was taken of this necessity to obtain test data on different conductor configurations. Configurations tested were 1) 2-3.05 cm conductors per pole, 2) $2-3.05 \mathrm{~cm}$ on one pole and $1-3.05 \mathrm{~cm}$ on the other pole, and 3) $1-3.05 \mathrm{~cm}$ per pole. Analyses of data obtained for these configurations will be reported in the next Technical Progress Report.

\section{Task 2: Study of Space Charge Generation Characteristics of DC Conductors}

To date, only preparatory work for this task has been undertaken: The monopolar test cage has been strung with a $4-3.05 \mathrm{~cm}$ conductor bundle, similar to that used on the dc test line for DOE Contract EC-77-C-01-5059. The test cage has a square cross section of side approximately $8 \mathrm{~m}$ and is approximately $14 \mathrm{~m}$ in length. The cage can be-electrically isolated from ground, or connected to ground through a known resistance, for measuring total conductor current. Additional ion current measurements will be made using $1 \mathrm{~m}^{2}$ collection plates at the center of each of the four walls of the cage. Electric fields will be measured using field probes also located at the center of the four walls. The cage is also equipped to measure the audible noise produced by the conductors.

Thanaei G.Comber

Michael G. Comber

Research Engineer-Program Coordinator Project UHV

September 4, 1980 


\section{APPENDIX A}

HVDC FACILITIES AT PROJECT UHV

M. G. Comber April 3, 1980 


\section{INTRODUCTION}

Under DOE Contract EC-77-C-01-5059, a $\pm 750 \mathrm{kV}$ ac-dc converter station was designed and constructed at Project UHV. This station (Figure 1) is based on the principal of a half-wave voltage doubler, in which the dc output is equal to twice the peak of the ac input. The station is modular in concept, consisting of high voltage capacitor and diode components which can be interconnected in a number of arrangements to provide bipolar operation at voltages up to $\pm 750 \mathrm{kV} \mathrm{dc}$, or monopolar voltages up to + or - 1500 $\mathrm{kV} \mathrm{dc}$. The ac feed to the station is via one of several power transformers and one of two regulating transformers installed at Project UHV under previous ac research programs.

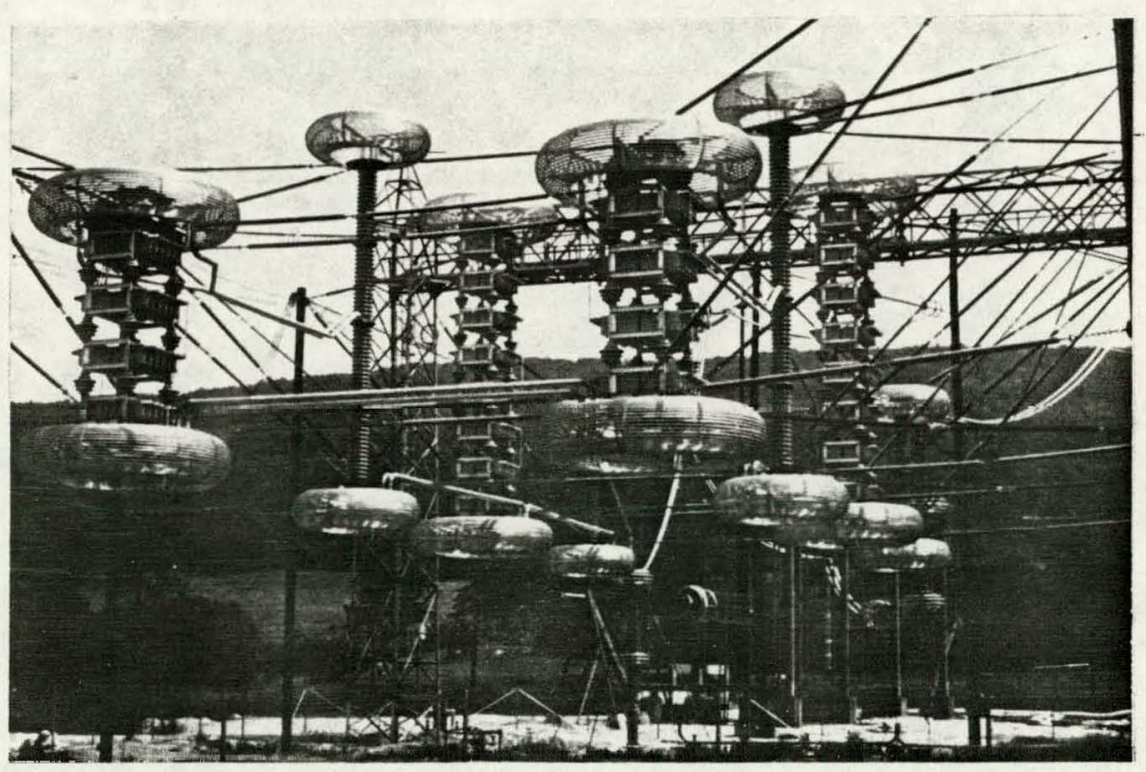

Fig. $1 \pm 750 \mathrm{kV}$ ac-dc Converter Station

In 1979, EPRI funded Project UHV, under program RP1282-1, to expand the dc facilities in anticipation of an extensive program of research into hydc transmission. Included in this expansion program were:

- A second $1500 \mathrm{kV} \mathrm{dc}$ power supply to be used in conjunction with the existing converter station to provide bipolar voltages up to $\pm 1500 \mathrm{kV}$ for transmission line testing.

- A bipolar dc test line capable of being energized at voltages up to $\pm 1500 \mathrm{kV}$, with the provision for rapid variation of pole spacing and height above ground. This line, the "main dc line," would complement an existing test line, the "short dc line," constructed 
under DOE program EC-77-C-01-5059, and primarily designed for testing at voltages up to $\pm 600 \mathrm{kV}$. (The major elements of the main dc line were already in place in the form of a 3-phase ac test line constructed in 1974 under EPRI program RP68).

- An auxiliary $\pm 375 \mathrm{kV}$ converter station, in concept similar to the existing converter station, which could be used as a separate power supply for testing the short dc line at voltages up to $\pm 375 \mathrm{kV}$ or for testing insulators in the hv insulator test chamber at voltages up to + or $-750 \mathrm{kV}$. Alternatively, the auxiliary station could be used in conjunction with the existing station to contemporaneously provide bipolar voltages up to $\pm 750 \mathrm{kV}$ for line testing and monopolar voltage up to + or - $1500 \mathrm{kV}$ for insulator testing.

The locations of the new dc facilities, with respect to the existing dc and ac facilities, are shown in the plot plan of Figure 2.

Following is a more detailed description of the new dc facilities, and a report on some of the operational problems encountered and steps taken to solve these problems.

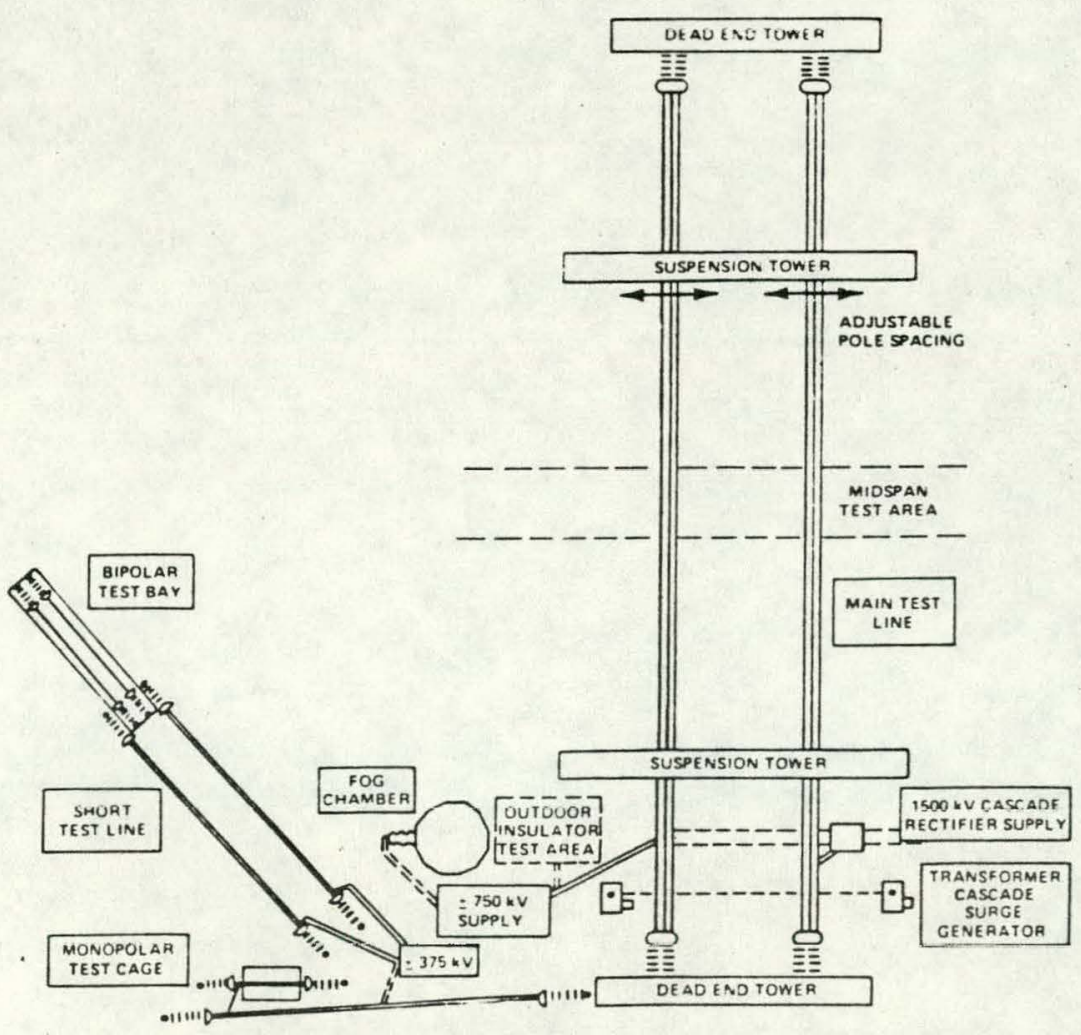




\section{MAIN DC TEST LINE}

The main dc test 1 ine is $520 \mathrm{~m}$ long, consisting of a bipolar arrangement of conductors in one main span of $340 \mathrm{~m}$ and two dead-end spans of $90 \mathrm{~m}$. The first line configuration (Figure 3) uses 6-conductor bundles of $5.59 \mathrm{~cm}$ diameter all-aluminum expanded conductors with a bundle diameter of $101.6 \mathrm{~cm}$. Nominal test voltage for this configuration is $\pm 1200 \mathrm{kV}$. The conductors,

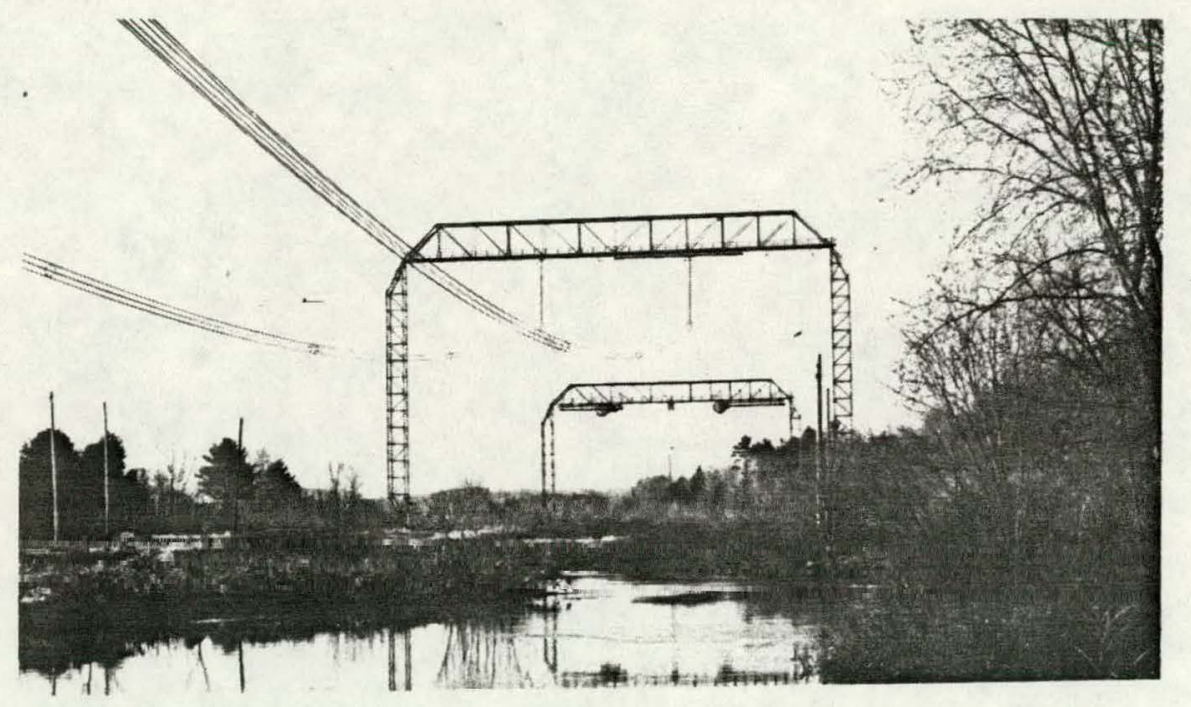

Fig. 3 Main Bipolar dc Test Line

the dead end towers and insulators, and the suspension towers, were all part of the last 3-phase ac line tested under EPRI program RP68-4.

A major addition to the line is the provision for rapid variation of pole spacing. To accomplish this, the V-string suspension insulators used in the ac program were replaced with vertical strings suspended form trolleys (Figure 4) which can be moved via a winch and cable system. The winches (Figure 5) are situated at ground level at the base of both suspension towers. To assist the spacing change, the cable system is equipped with large counterweights (Figure 6) at the two suspension towers. For the first line configuration, a nominal pole spacing of $24.5 \mathrm{~m}$ has been chosen, with planned periodic variations in spacing from $17 \mathrm{~m}$ to $32 \mathrm{~m}$ (the system provides the capability of varying the spacing down to $12 \mathrm{~m}$, but this will not be used for the first configuration). The change from the minimum to the maximum spacing can be accomplished in approximately 30 minutes, and can be undertaken with the line energized. The change is effective on $1 y$ over the main suspension span, since the dead-end terminations are fixed at 


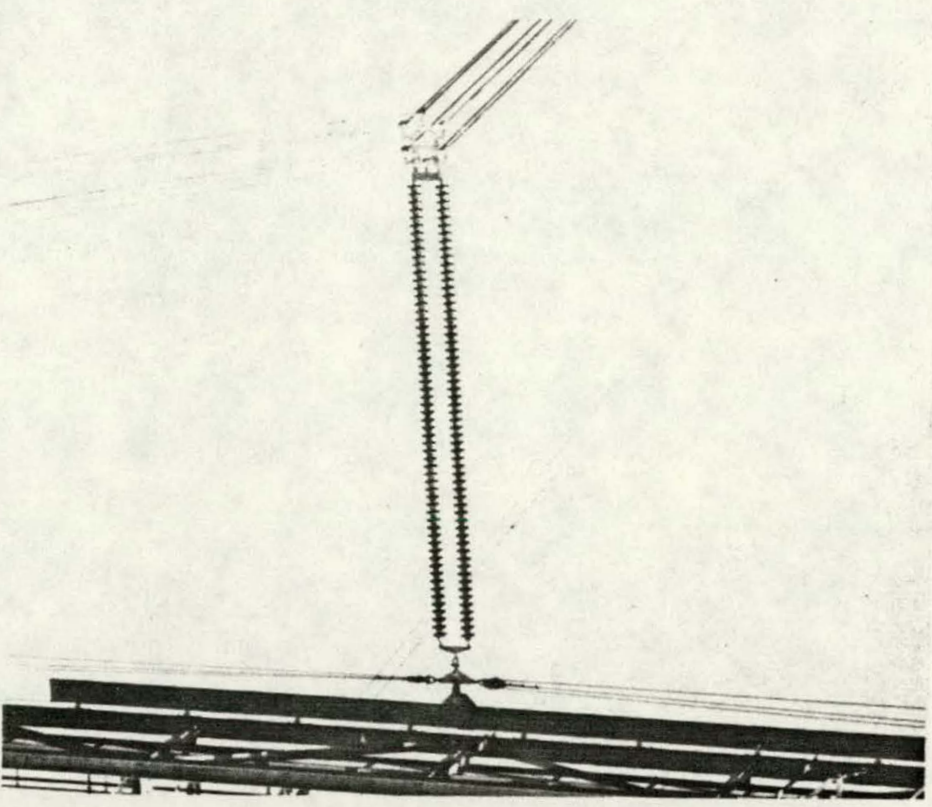

Fig. 4. Vertical suspension string and adjustable trolley on main dc line.

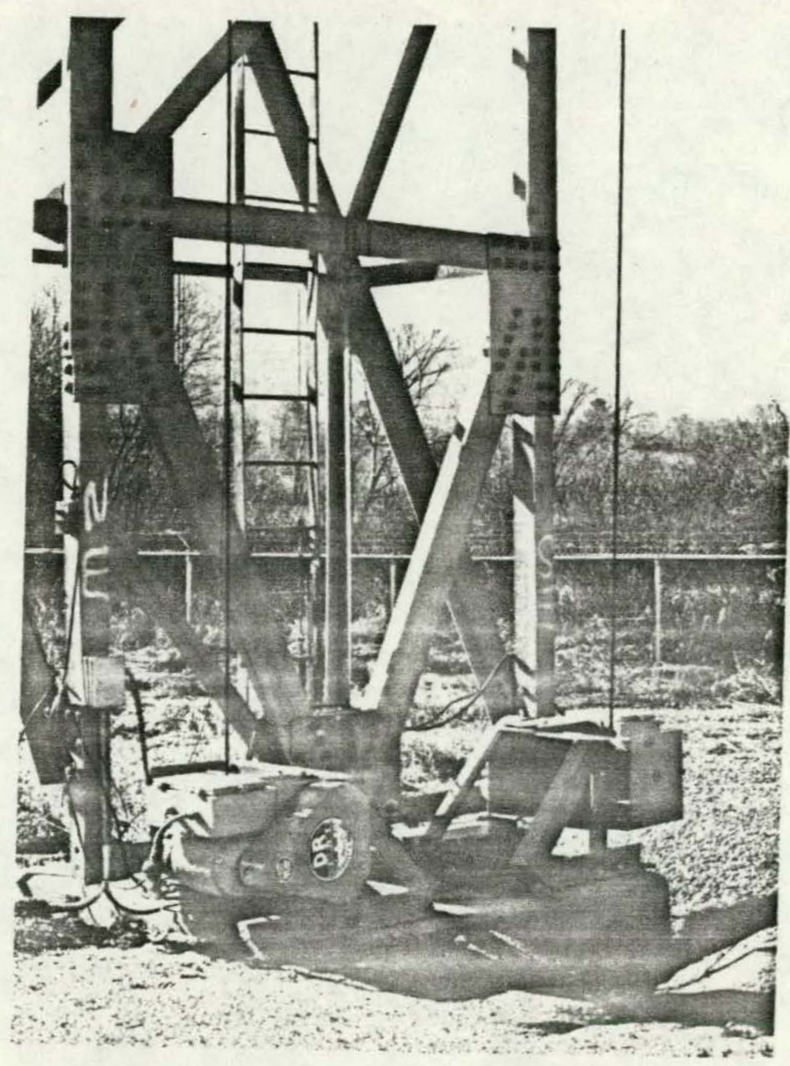

Fig. 5. Winches for main line pole spacing change. 


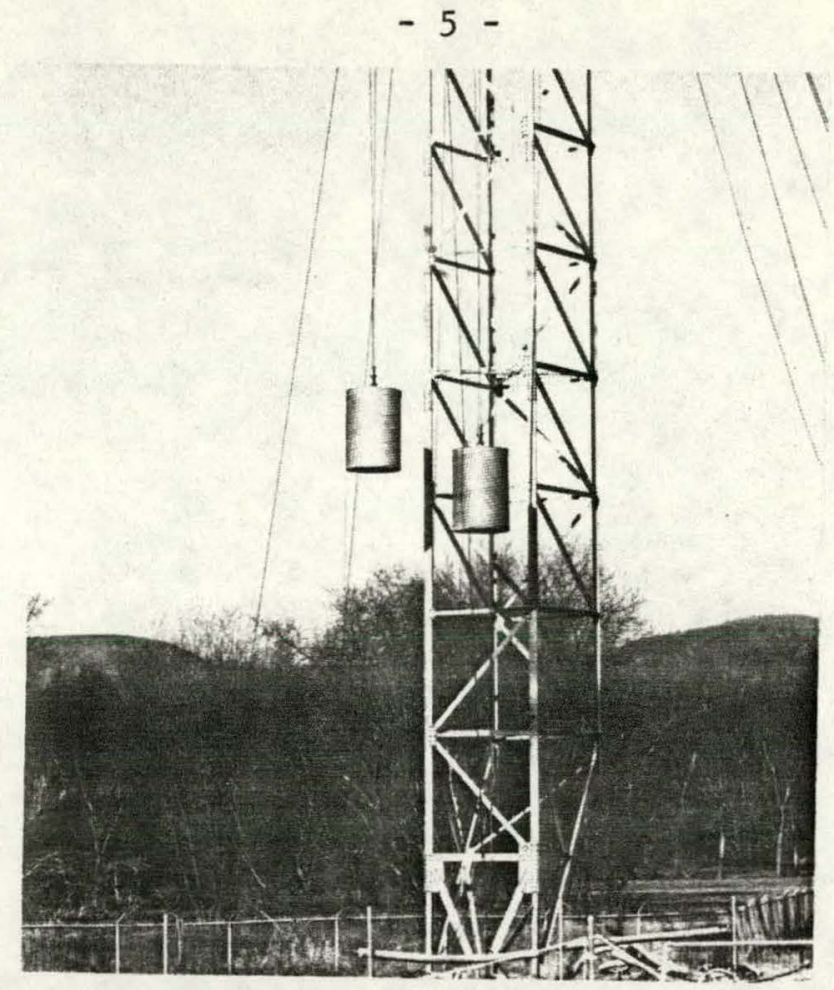

Fig. 6 Counterweights Used to Assist Main dc Line Pole Spacing Change.

the nominal pole-spacing (the dead-ends are themselves on trolleys, but these are pinned and cannot be quickly moved; for major changes in configuration - for example, the second configuration to be tested will have a $15.25 \mathrm{~m}$ nominal spacing with variations from $12 \mathrm{~m}$ to $18.5 \mathrm{~m}$ - the deadend trolleys would be pinned at the new nominal spacing).

Another major feature of the line, and one which was used in the ac program, is the capability of rapidly varying the sag over the suspension span, thus creating the ability of testing several different line heights within a relatively short period of time. This feature is accomplished by a system of winches beyond each dead-end tower (Figure 7). For the first

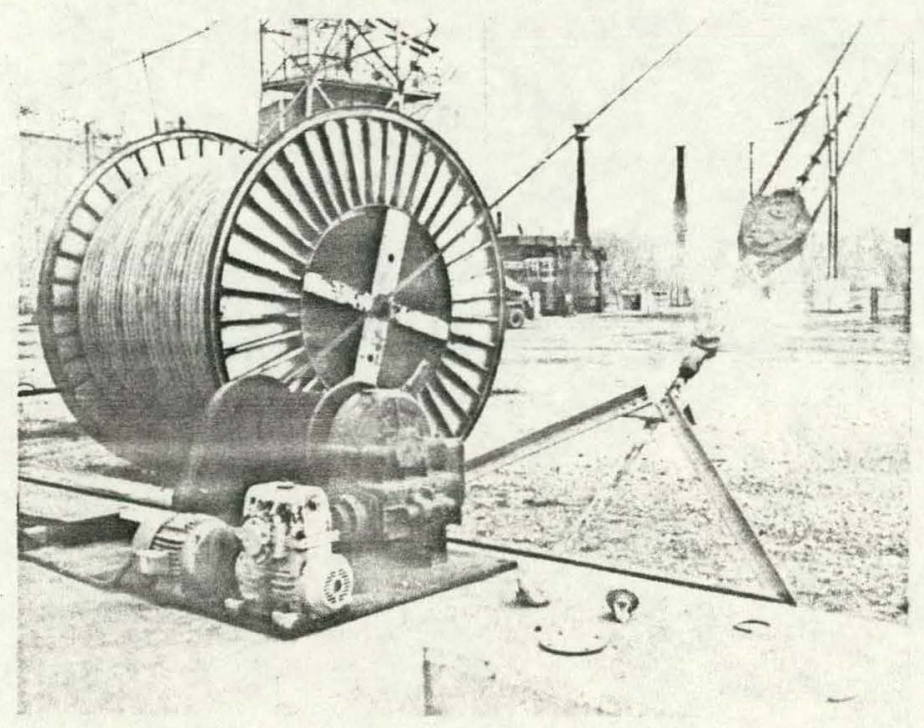

Fig. 7 Winch for variation of Main dc Line Conductor Height 
configuration of 6-conductor bundles, the line can tolerate changes in midspan height from $15 \mathrm{~m}$ to $24.5 \mathrm{~m}$ (the minimum value is governed by allowable swing of the suspension insulators, while the maximum value is governed by tension limits in the dead-end winch system).

Insulators used at dead-ends and suspension points are given in Table 1.

\begin{tabular}{|c|c|c|c|c|c|c|c|}
\hline \multirow[b]{2}{*}{ Location } & \multirow[b]{2}{*}{ Type } & \multirow{2}{*}{$\begin{array}{c}\text { Mechanical } \\
\text { Strength } \\
(\mathrm{kN})\end{array}$} & \multicolumn{3}{|c|}{$\begin{array}{l}\text { Dimensions of } \\
\text { Units (mm) }\end{array}$} & \multirow{2}{*}{$\begin{array}{l}\text { No. of } \\
\text { Paralle1 } \\
\text { Strings }\end{array}$} & \multirow{2}{*}{$\begin{array}{l}\text { No. of } \\
\text { Units } \\
\text { Per String }\end{array}$} \\
\hline & & & Diam. & Length & Creep & & \\
\hline Dead ends & $\begin{array}{l}\text { Locke } \\
\text { porcelain }\end{array}$ & 22700 & 292 & 156 & 381 & 4 & 55 \\
\hline $\begin{array}{l}\text { Suspension } \\
\text { (north } \\
\text { tower) }\end{array}$ & $\begin{array}{l}\text { Locke } \\
\text { porcelain }\end{array}$ & 22700 & 292 & 156 & 381 & 2 & 59 \\
\hline $\begin{array}{l}\text { Suspension } \\
\text { (south } \\
\text { tower) }\end{array}$ & $\begin{array}{l}\text { Sediver } \\
\text { glass }\end{array}$ & 54500 & 381 & 233 & 716 & 1 & 42 \\
\hline
\end{tabular}

\section{$1500 \mathrm{kV}$ DC GENERATOR}

For line testing purposes, the high current rating ( $5 \mathrm{~A}$ continuous) of the existing $\pm 750 \mathrm{kV}$ converter station is not necessary. Thus the constraints imposed in the design of the original station did not apply for the second $1500 \mathrm{kV}$ pole. Consequently, the dc supply chosen for the second pole was a more or less conventional cascade-rectifier set. The set, manufactured by Haefely, Ltd. of Switzerland, is actually a "symmetrical-cascade" hvdc generator based on the Cockcroft-Walton cascade rectifier principal but having a double set of input capacitor and diode units to provide a higher current, lower ripple and regulation ratings. The generator, installed on rails at Project UHV is shown in Figure 8. The electrical configuration of the generator is shown schematically in Figures 9 and 10 .

The generator is fed with alternating voltage from two $480 \mathrm{~V}-165 \mathrm{kV}$ transformers manufacturerd by Haefely's United States affiliate, American High Voltage Test Systems (AHVTS) of Accident, Md. The primary voltage of these transformers is controlled over the range $0-480 \mathrm{~V}$ by a thyristorcontrolled regulating system which can provide rapid automatic control of the hvdc output. The generator is rated at $1500 \mathrm{kV} \mathrm{dc}, 250 \mathrm{~mA}$. It is equipped with a hydraulically-operated polarity reversal mechanism and a pneumatically operated grounding system. A current limiting resistor of $24 \mathrm{k} \Omega$ is 


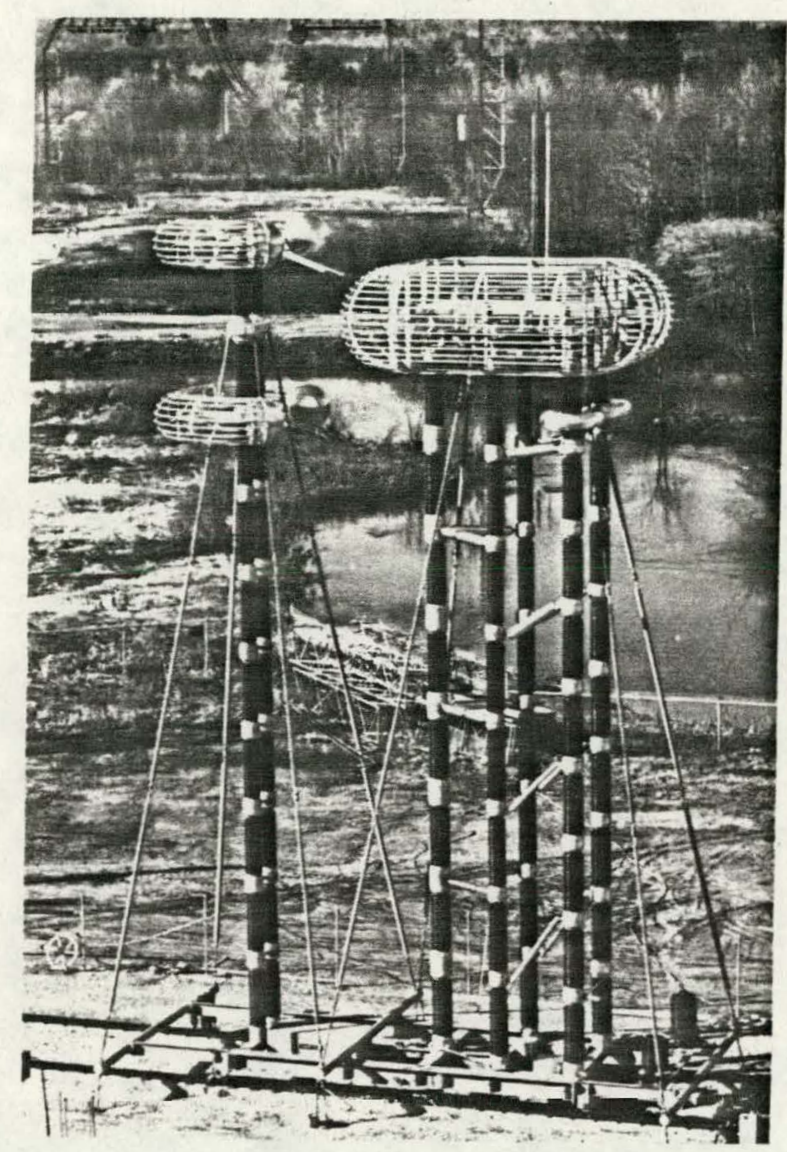

Fig. 8 Haefely $1500 \mathrm{kV}$ dc Generator Installed at Project UHV

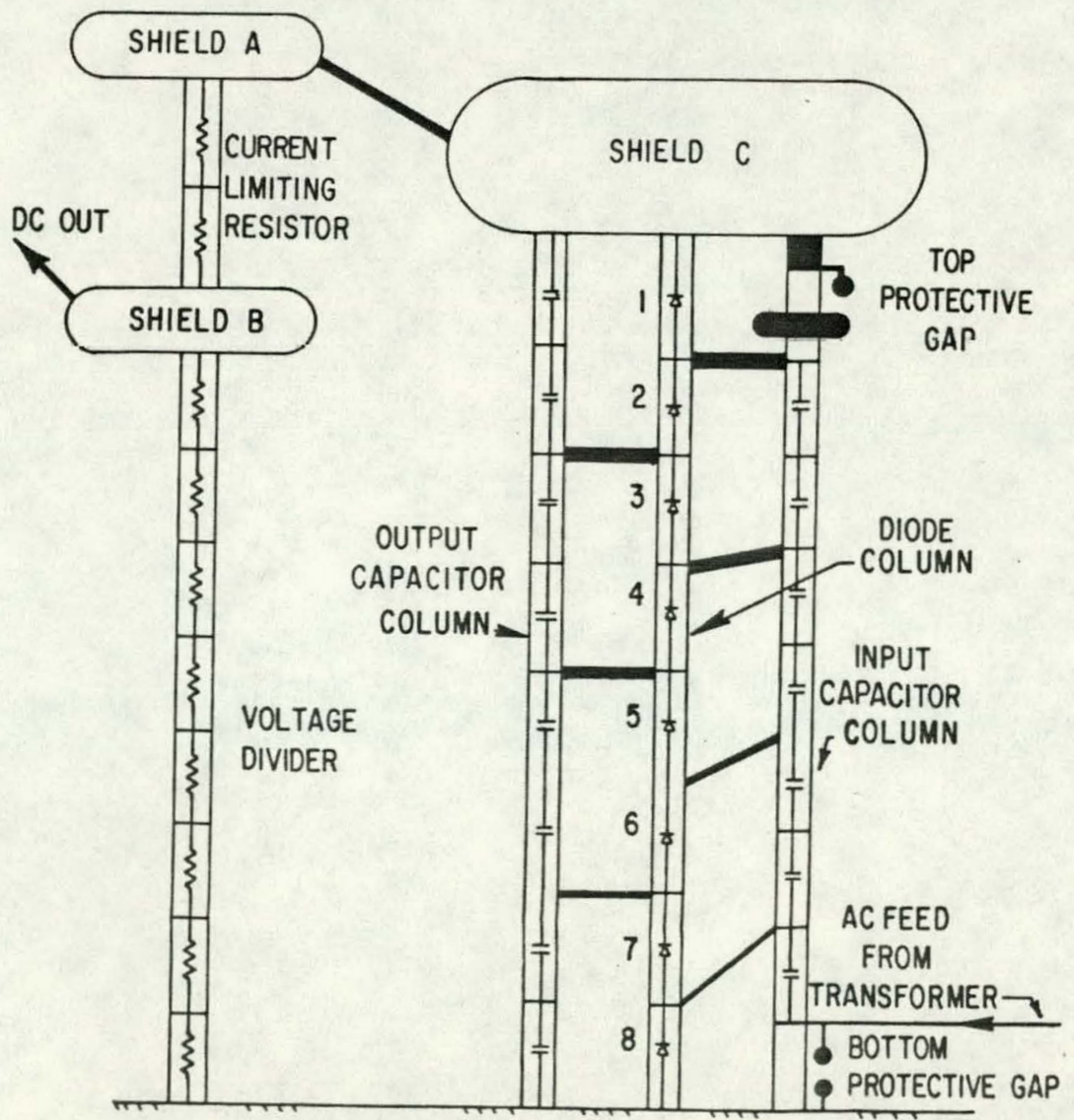

Fig. 9 Schematic Diagram of Haefely Generator Electrical Connections (positive polarity connections shown) 


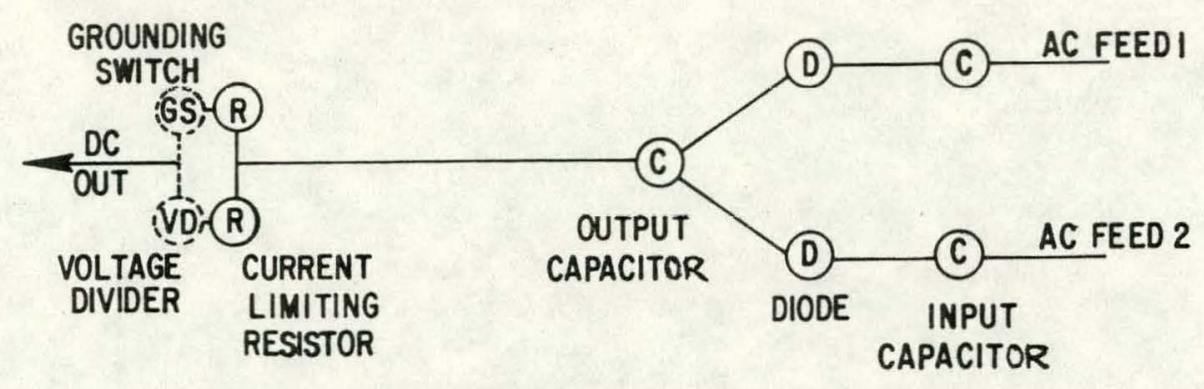

Fig. 10 Schematic Plan of Haefely Symmetrica1-cascade Connections (grounding switch parallels voltage divider and is connected between ground and shield B - Figure 9).

used to dampen overvoltages on the diode column in the case of a flashover to ground of the test object. The Voltage divider has a total resistance of $3000 \mathrm{M}$ and is capacitively compensated for good high frequency response.

A number of operational problems, including failures of components, have been experienced. The first of these occurred during operation of $+1500 \mathrm{kV}$ on a very cold, low humidity night. On a partial flashover of the diode column, initiated by corona on flange bolts, the protection system operated as designed but resulted in failure of two diode units. The sequence of events was as follows: 1) the partial flashover initiated a generator trip and an immediate operation of the grounding switch, 2) the grounding switch operated, putting shield $B$ at ground potential, instantaneously establishing a potential difference of $1500 \mathrm{kV}$ between shields $\mathrm{C}$ and $\mathrm{B}, 3$ ) the gap between shields C and B flashed over, putting shield C at ground potential (this flashover was not an expected occurrence - the gap should have withstood the voltage until this was drained to ground through the current limiting resistor, 4) the output capacitor column discharged rapidly through this fault, and the input capacitor column simultaneously discharged through diodes $\equiv_{1} 1,3,5$ and 7 ; however, the discharge of the input capacitors occurred more slowly than that of the output capacitors (due to resistance built into the diode units) resulting, at the very first instant, in the full voltage of the input capacitor column appearing across diode unit 非; as a consequency diode unit 非 2 in both diode columns failed due to overvoltage. The generator was subsequently disassembled to remove the damaged diodes which were themselves completely disassembled and repaired on site by Project UHV and Haefely personnel. The repair and reassembly of the generator was effected within 3-1/2 weeks. To prevent a reoccurrence of this accident, a time delay. was built into the grounding switch system. With this delay, the output voltage will decay to about $900 \mathrm{kV}$, from $1500 \mathrm{kV}$, before operation of the switch. Additionally, an external porcelain-enclosed resistor has been supplied by Haefely to provide additional protection in the event of a flashover of the test object (see Figure 11). 


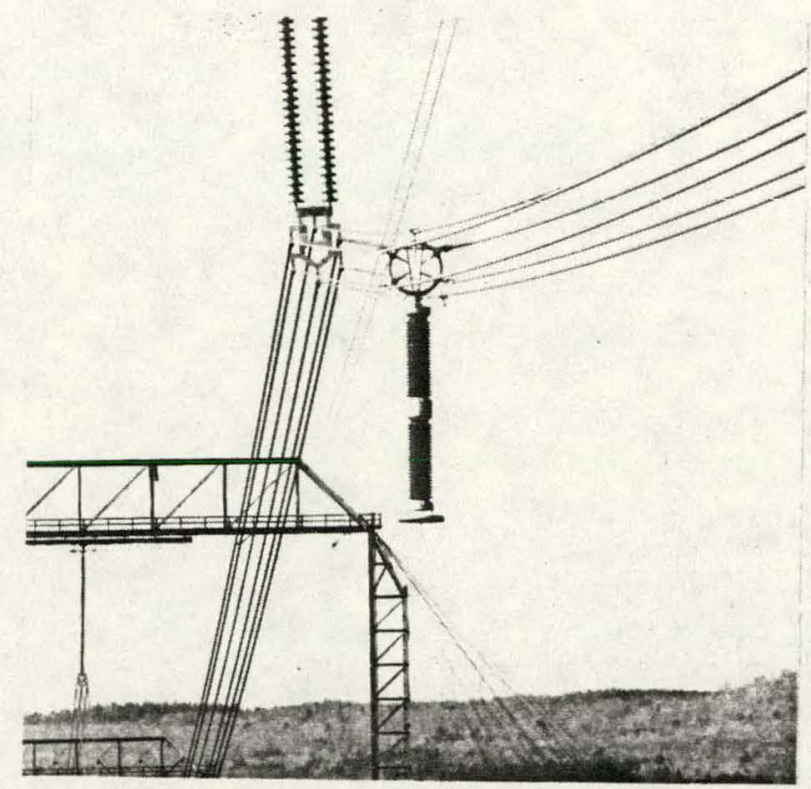

Fig. 11 Externa1 Porcelain Enclosed Resistor Connected Between Generator and Test Object.

Perhaps as a result of the flashover described above, damage was also caused to the thyristor control unit, requiring the replacement of the thyristors. Additionally it was discovered that the high voltage bushing of one of the feed transformers had failed. A review of the design revealed that the bushing rating was only marginally suitable for the normal maximum operating voltage of the transformer. Consequently, the transformers were refitted with new, higher rated bushings, an operation which consumed approximately one month.

Following the return of the transformers, acceptance testing of the generator resumed. During tests in light snow at voltages in the 1200-1500 $\mathrm{kV}$ range, operation of both top and bottom protective gaps occurred, presumably due to a reduction in the gap strength caused by snowflakes settling on the electrodes (the electrodes were designed with rain shields, but apparently the effect of snow had been overlooked). With properly set gaps, such occurrences should cause a normal trip-out, and such a trip-out did occur for most of the gap operations. However, a side-effect of the operation of the bottom gaps was to place a short circuit on the transformers across which the gaps were directly placed. A result of many such operations was an internal failure of one of the transformers which was subsequently returned to the manufacturer for repair.

Subsequent tests were conducted with one transformer feeding both input capacitors. This mode of operation does not reduce the voltage capabix lity, but limits the maximum current to one-half the normal rating, and results in twice the percentage ripple and voltage regulation. During these tests, the latest, and hopefully last, major failure occurred. In an attempt to avoid premature operation of the bottom protective gaps, these gaps were installed in temporary porcelain housings (Figure 12). In addition a $3 \mathrm{k} \Omega$ 


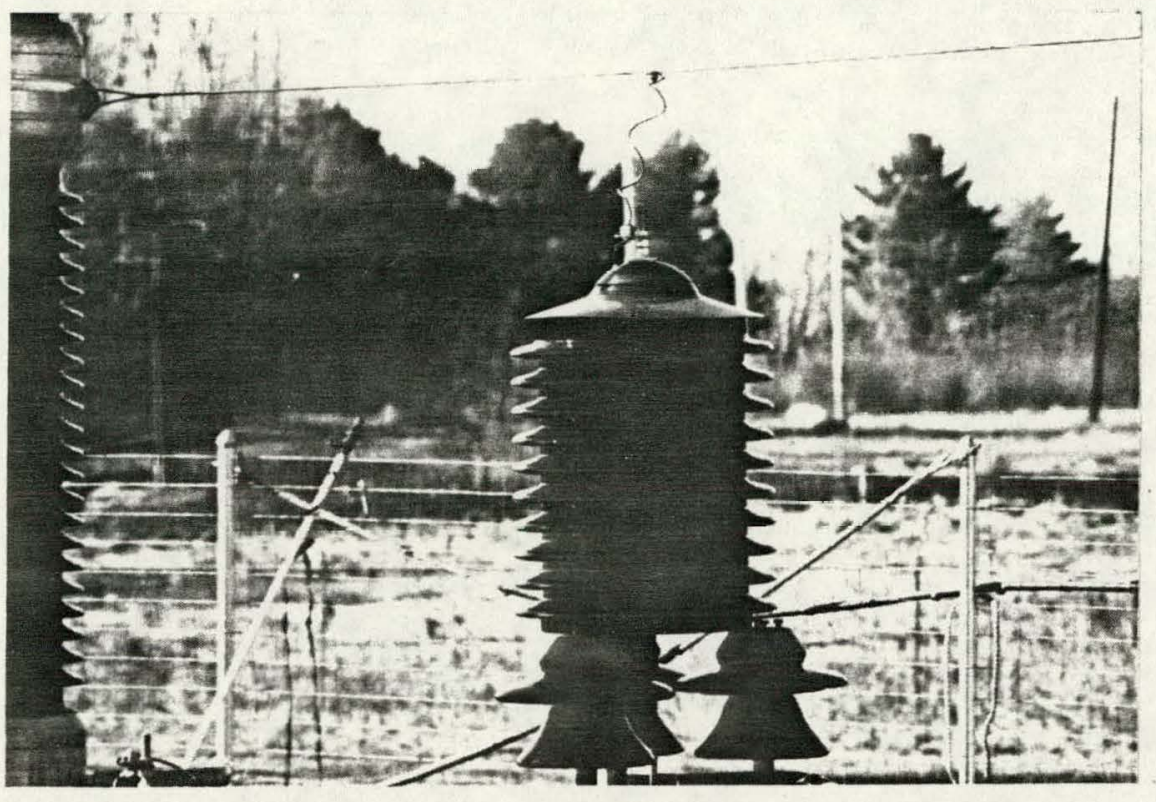

$\begin{array}{ll}\text { Fig. } 12 & \text { Temporary Porcelain Housing for Bottom } \\ \text { Protective Gap }\end{array}$

resistor was placed in series with the gap to provide a modicum of damping to protect the remaining transformer. During operation at $+1280 \mathrm{kV}$ in fair weather, an operation of the top gap occurred. This operation caused the input capacitor column to rise up in voltage by an amount equal to the voltage across the last diode stage at the time of gap operation (this can be seen to be one-quarter of the total dc voltage, or $320 \mathrm{kV}$ in this particular case). At the instant of gap operation, diodes 非1, 3, 5 and 7 are non-conducting while 非2, 4,6 and 8 are conducting. Thus the voltage across diode 非 8 was zero immediately preceding the gap operation, and immediately afterward should have been only $320 \mathrm{kV}$, well within the rating of the diode unit. However, it appears that the LC circuit made up of the input capacitor column, stray capacitance of the transformer, and the inductance of connections, combined with very little resistance, resulted in a very highfrequency voltage ringing which could produce a rapid doubling of voltage across the bottom diode. Normally the increased voltage should cause operation of the bottom gap, thus protecting the diode. In this instance however, it seems that the operation of the bottom gap was retarded by the effect of the $3 \mathrm{k} \Omega$ series resistor, the net result being failure due to overvoltage of the bottom diode (非8) in one of the two columns. The generator was again disassembled, the diode repaired on site, and the generator reassembled and put back into operation. This exercise was accomplished in only one week.

Additional steps which are being undertaken by Haefely to prevent reoccurrences of these failures are: 
- replacement of the exposed spark gaps by multi-stage porcelain enclosed gaps (at both top and bottom)

- installation of a $1 \mathrm{k} \Omega$ resistor in the ac feed, between the transformer and the input capacitor (and removal of the resistor direct1y in series with the bottom gap); low voltage flashover tests with this arrangement showed that overvoltages across the bottom diodes would be completely eliminated

\section{$\pm 375 \mathrm{kV}$ AUXILIARY AC-DC CONVERTER STATION}

The auxiliary converter station is similar in concept to the main \pm $750 \mathrm{kV}$ converter station. The arrangement of capacitors and diodes are, however, ground supported (Figure 13) rather than suspended as in the \pm $750 \mathrm{kV}$ station. Current rating is identical to the $\pm 750 \mathrm{kV}$ station while voltage rating is one-half.

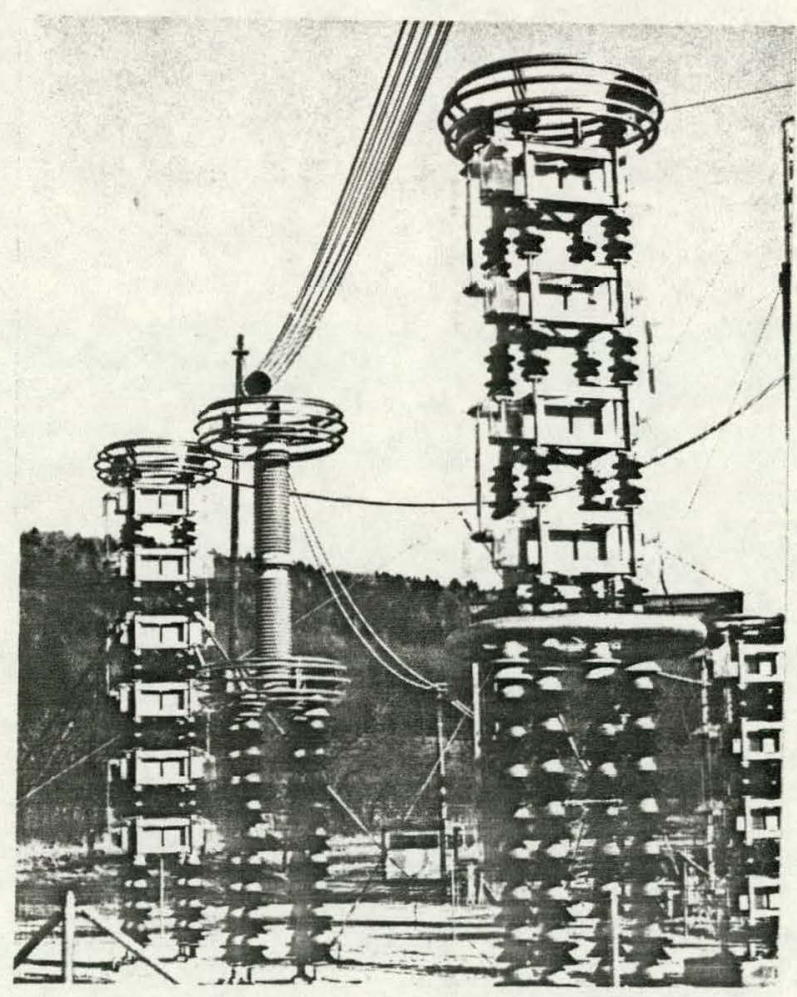

Fig. 13 Ground-Supported Capacitors and Diodes in $\pm 375 \mathrm{kV}$ Auxiliary Converter Station

The components can be connected in several different modes to provide bipolar voltages (Figure 14) or monopolar voltages (Figures 15 and 16 ). 


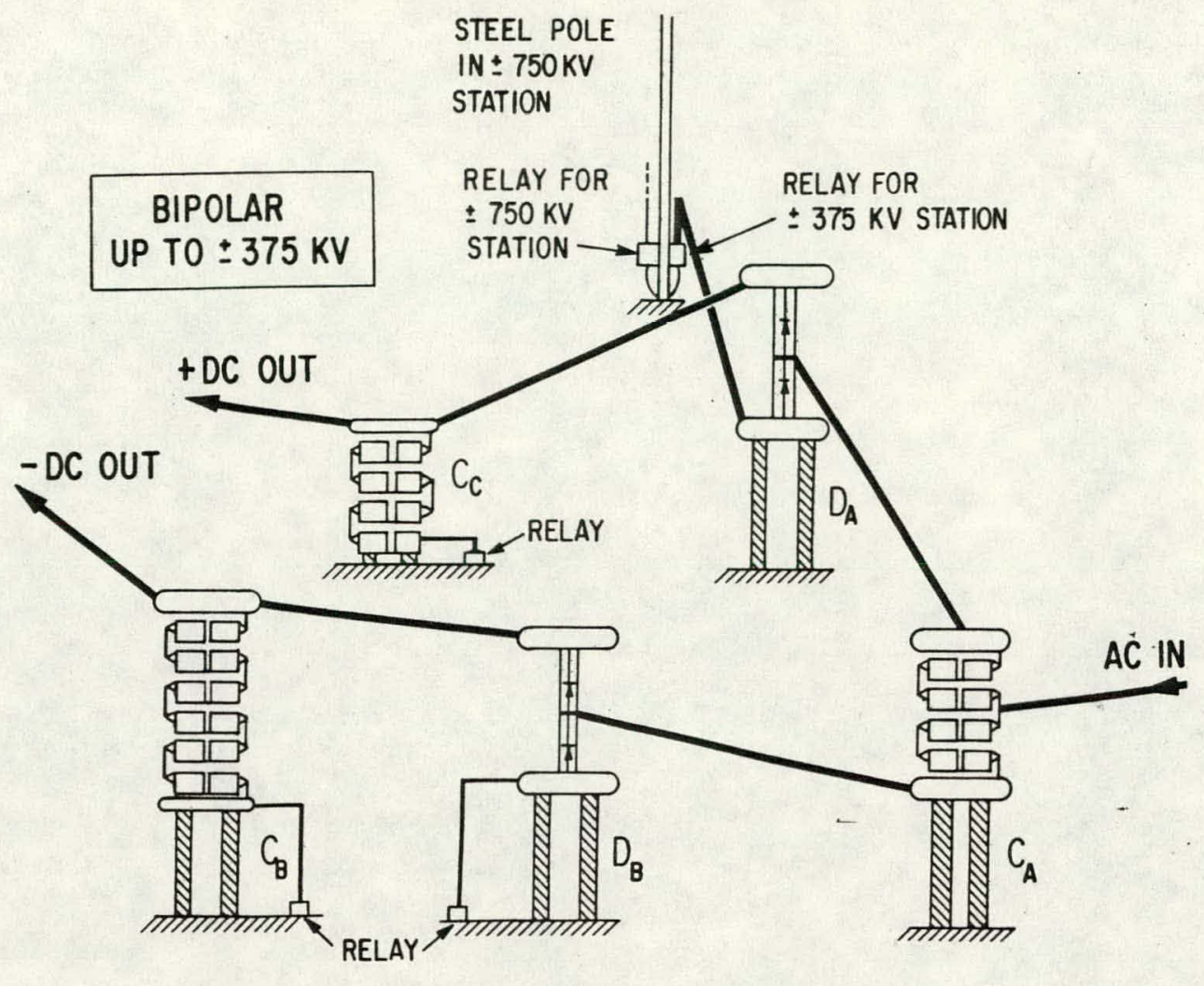

Fig. 14. Schematic diagram of auxiliary converter station in bipolar mode.

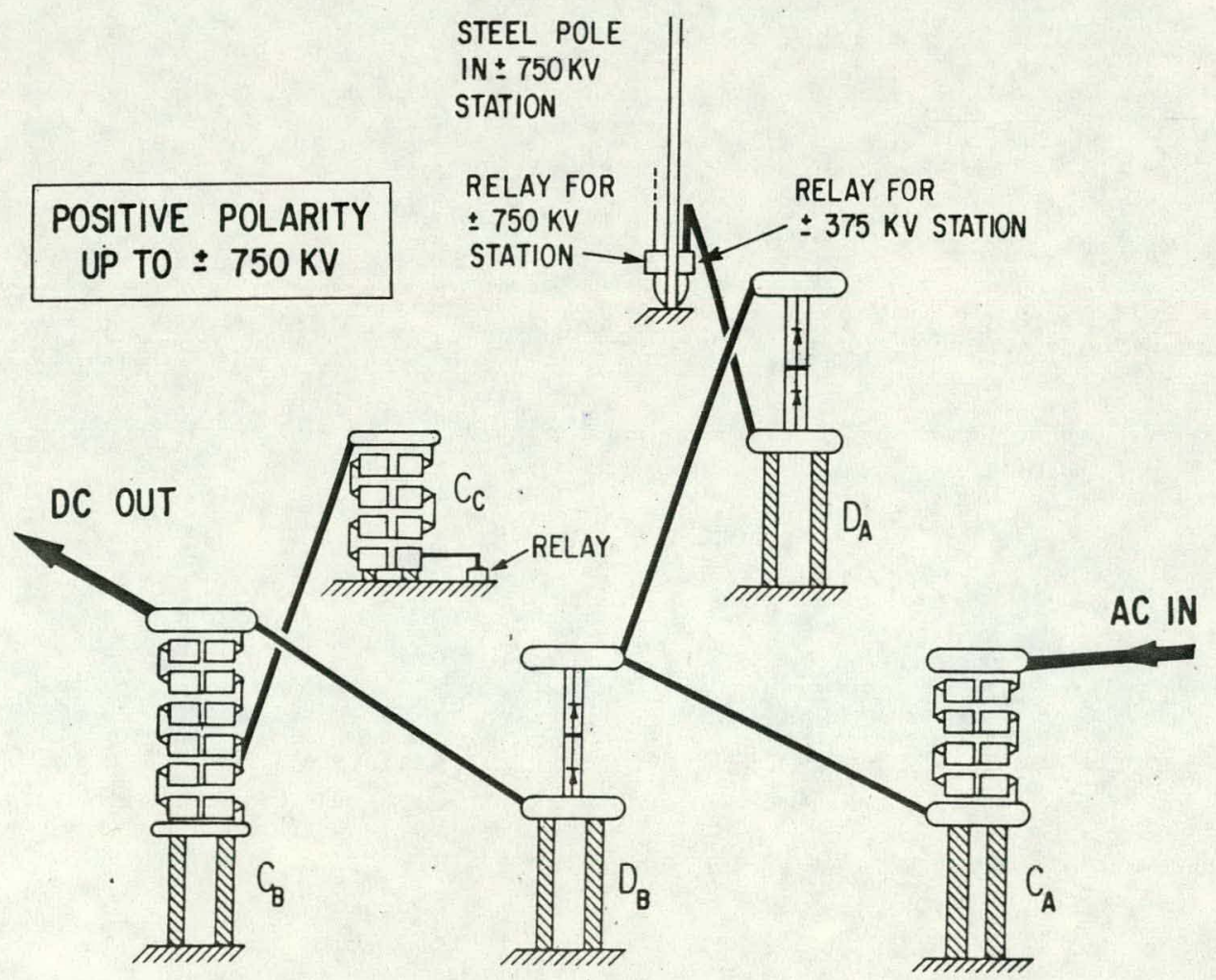

Fig. 15. Schematic diagram of auxiliary converter station in monopolar positive mode. 


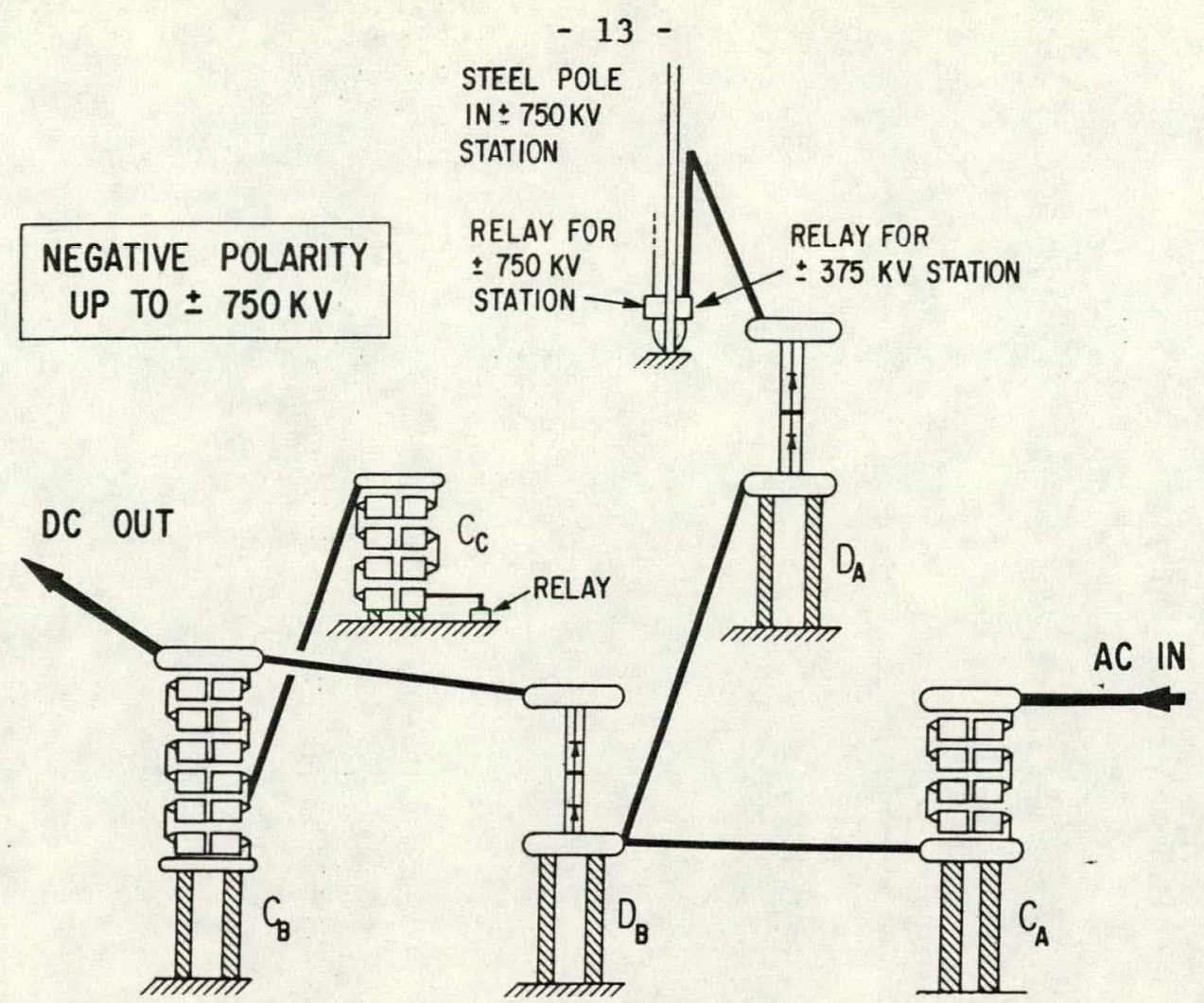

Fig. 16 Schematic Diagram of Auxiliary Converter Station in Monopolar Negative Mode.

Operation of this station has also not been without major problem. During initial performance tests in the monopolar negative mode, an unanticipated ground fault occurred to the output. As no flashover was anticipated, no current limiting resistance was included in the circuit, the net result of this being that all four diode units failed due to overcurrent. As was the case with the Haefely diodes, these damaged units were also repaired in house. The constrution of those units was, however, considerably less amenable to disassembly than the Haefely units and consequently took considerably more effort to repair. The disassembly, repair and reassembly was effected in four weeks. During this time, current limiting resistors in the form of wire wound cards were installed in the ac feed to the station and in between stages of all three capacitor stacks (Figure 17). Such steps had previously been taken in the $\pm 750 \mathrm{kV}$ station. Low voltage flashover tests following reassembly of the $\pm 375 \mathrm{kV}$ station have shown that the resistors effectively reduce fault currents to well below the diode limits. 


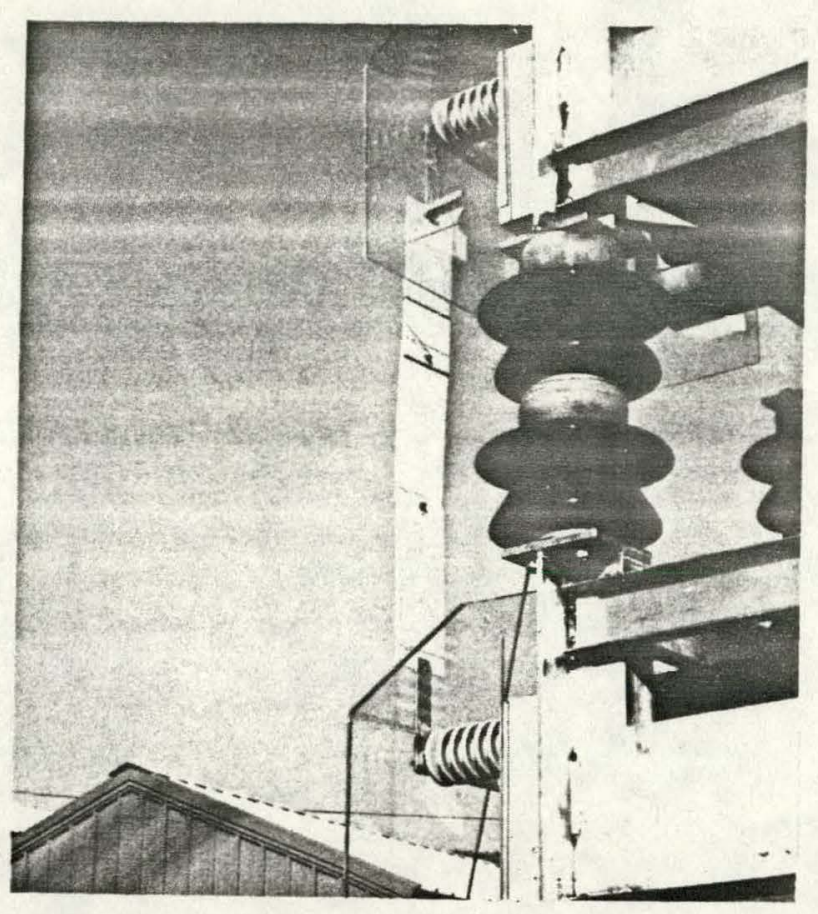

Fig. 17 Resistor "Cards" Between Capacitor Banks in $\pm 375 \mathrm{kV}$ Converter Station 


\section{APPENDIX B}

FAIR WEATHER ELECTR IC FIELD AND ION CURRENT PROFILES UNDER PROJECT UHV DC TEST LINE-PRELIMINARY RESULTS

G.B. Johnson

Aprị 22, 1980 
FAIR WEATHER ELECTRIC FIELD AND ION CURRENT PROFILES

UNDER PROJECT UHV DC TEST LINE-PRELIMINARY RESULTS

\section{INTRODUCTION}

The electric field and ion current profiles have been measured at ground level at midspan of a HVDC transmission line operating in a bipolar mode at various voltages and pole spacings. The electric field measurements were made using Monroe Field meters 'operated in an inverted geometry to allow use in foul weather. [1] The ion current measurements were made using one meter square collection plates such that the ion current was read out directly in nanoamperes per square meter. [2]

The current and field probes were postioned at 5 meter intervals along a test strip running perpendicular to the line at midspan. The height of the line at midspan was 19.5 meters for these tests. The line was a 6 conductor bundle of $5.6 \mathrm{~cm}$ conductor on a $102 \mathrm{~cm}$ diameter bundle. Field and current measurements were made with pole spacings of $17 \mathrm{~m}$ and $24.5 \mathrm{~m}$. The line was energized in a bipolar mode at voltages of $\pm 750 \mathrm{kV}, \pm 900 \mathrm{kV}$, $\pm 1050 \mathrm{kV}$, and $\pm 1200 \mathrm{kV}$.

\section{PRELIMINARY RESULTS}

The figures presented below are the result of a small collection of data in fair weather and should be taken only as a preliminary indication of the field and current profiles to be found under a HVDC transmission line. The values plotted in the following graphs are the averages of 20 readings taken during a 30 minute period for the particular line voltage and pole spacing that is indicated. A11 measurements were taken during fair weather conditions with the temperature varying from $2^{\circ} \mathrm{C}$ to $5^{\circ} \mathrm{C}$; relative humidity ranging from $54 \%$ to $48 \%$; and winds averaging $2.25 \mathrm{~m} / \mathrm{s}$ from the positive polarity pole to the negative polarity pole of the line.

Figure 1 shows the electric field profiles at ground level for the various line voltages with the pole-to-pole spacing set at $17 \mathrm{~m}$. The line height at midspan was $19.5 \mathrm{~m}$. Figure 2 is the corresponding profile for the ground level ion currents. Figures 3 and 4 are the field and current profiles with a pole-to-pole spacing of $24.5 \mathrm{~m}$. As can be seen from these 


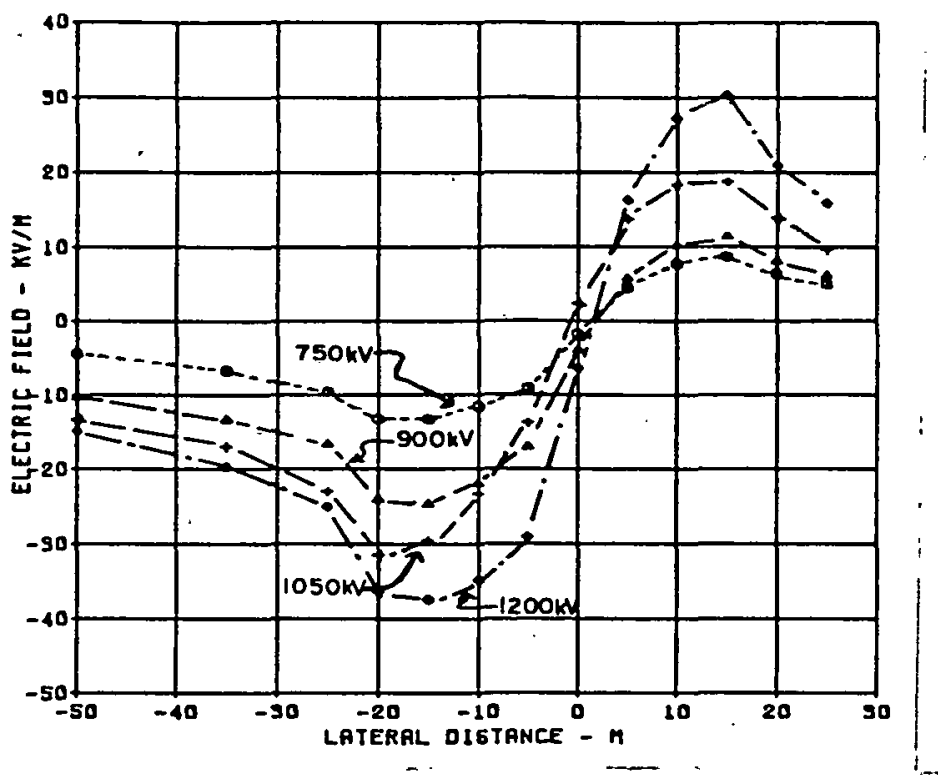

Fig. 1 Electric Field Profiles

$17 \mathrm{~m}$ pole spacing

Bipolar line voltages of $\pm 750 \mathrm{kV}$, $\pm 900 \mathrm{kV}, \pm 1050 \mathrm{kV}$, and $\pm 1200 \mathrm{kV}$.

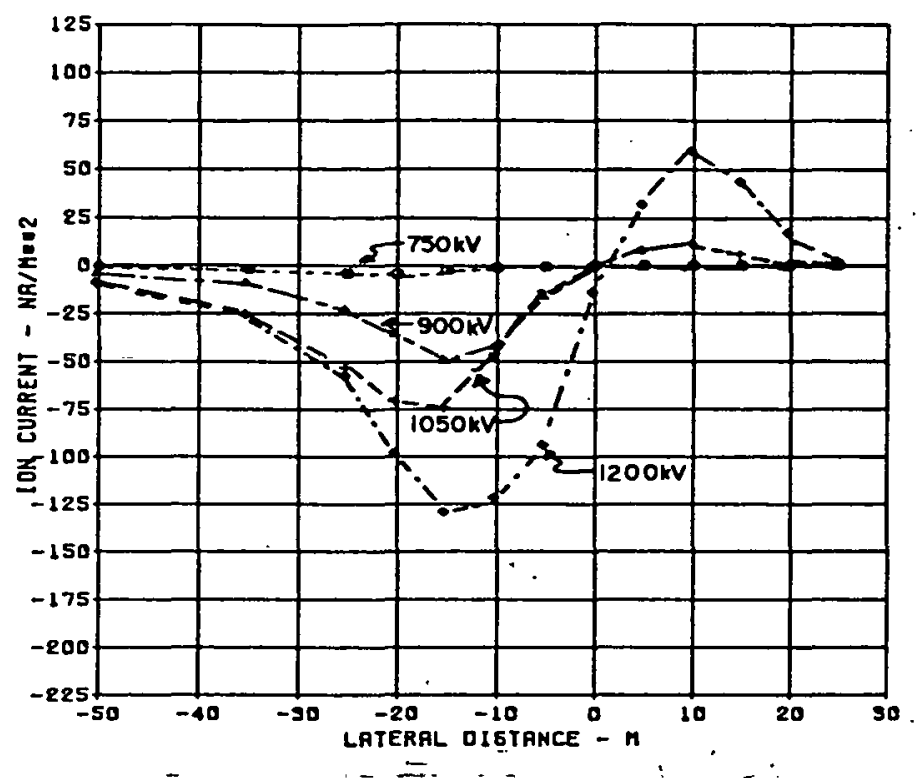

Fig. 2 Ion Current Profiles

$17 \mathrm{~m}$ pole spacing Bipolar 1ine voltages of $\pm 750 \mathrm{kV}$, $\pm 900 \mathrm{kV}, \pm 1050 \mathrm{kV}$, and $\pm 120 \overline{\mathrm{kV}}$.

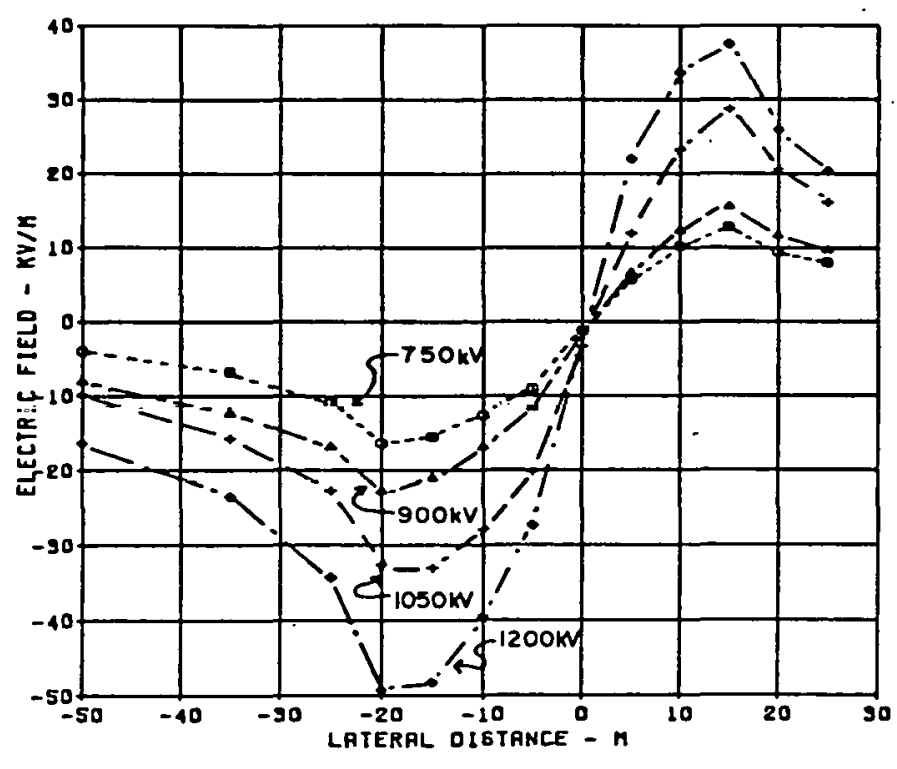

Fig. 3 Electric Field Profiles $24.5 \mathrm{~m}$ pole spacing Bipolar line voltages of $\pm 750 \mathrm{kV}$, $\pm 900 \mathrm{kV}, \pm 1050 \mathrm{kV}$, and $\pm 1200 \overline{k V}$.

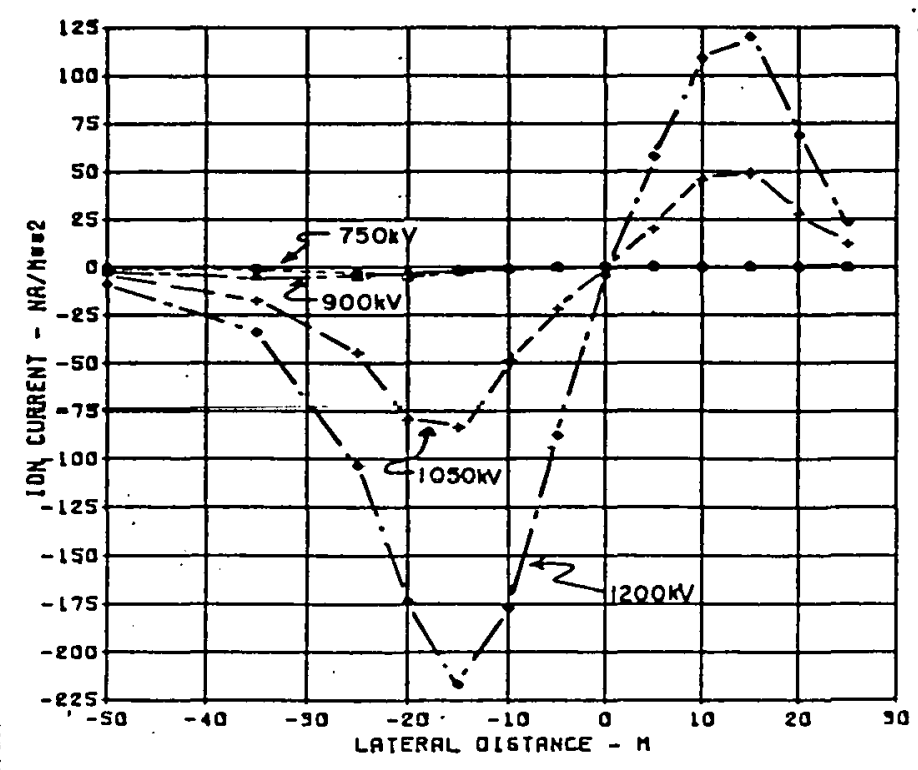

Fig. 4 Ion Current Profiles $24.5 \mathrm{~m}$ pole spacing Bipolar line voltages of $\pm 750 \mathrm{kV}$, $\pm 900 \mathrm{kV}, \pm 1050 \mathrm{kV}$, and $\pm 1200 \mathrm{kV}$. 
figures, the negative polarity ion currents exceed, by roughly a factor of 2, the positive polarity ion currents, while the peak negative fields are about 1.4 times greater than the peak positive fields.

Figures 5 and 6 are a comparison of the field and ion current profiles for the two pole spacings $(17 \mathrm{~m}$ and $24.5 \mathrm{~m})$ with the 1 ine energized to $\pm 750 \mathrm{kV}$. There is very little corona activity on the line as indicated by the small values of ion current collected at ground, thus the field profiles are similar to thnse calculated for the purely electrostatic case. The electrostatic field profiles are shown in Fig. 7. The fields are calculated for a bipolar 1ine voltage of $100 \mathrm{kV}$ and scale directly with the line voltage.

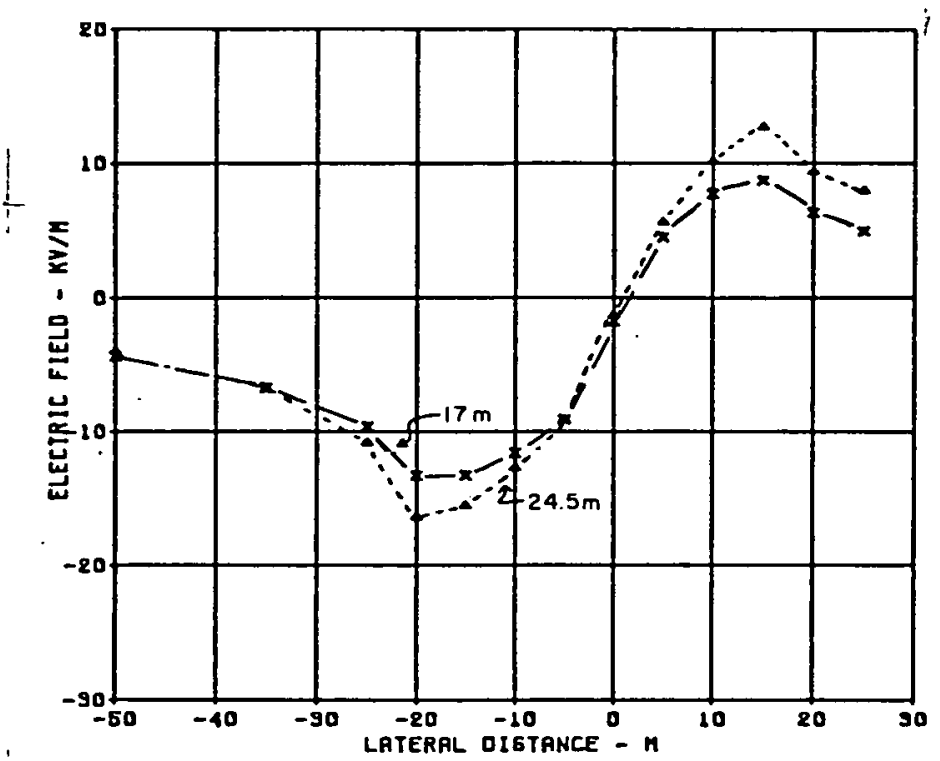

Fig. 5 Electric Field Profiles $\pm 750 \mathrm{kV}$

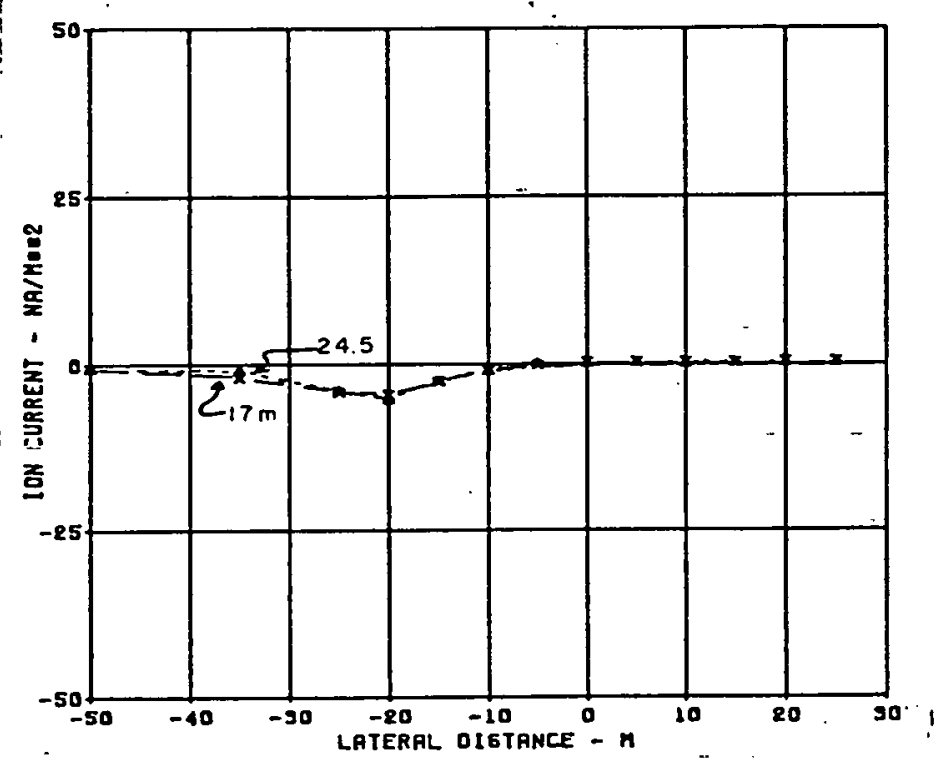

Fig. 6 Ion Current Profiles $\pm 750 \mathrm{kV}$

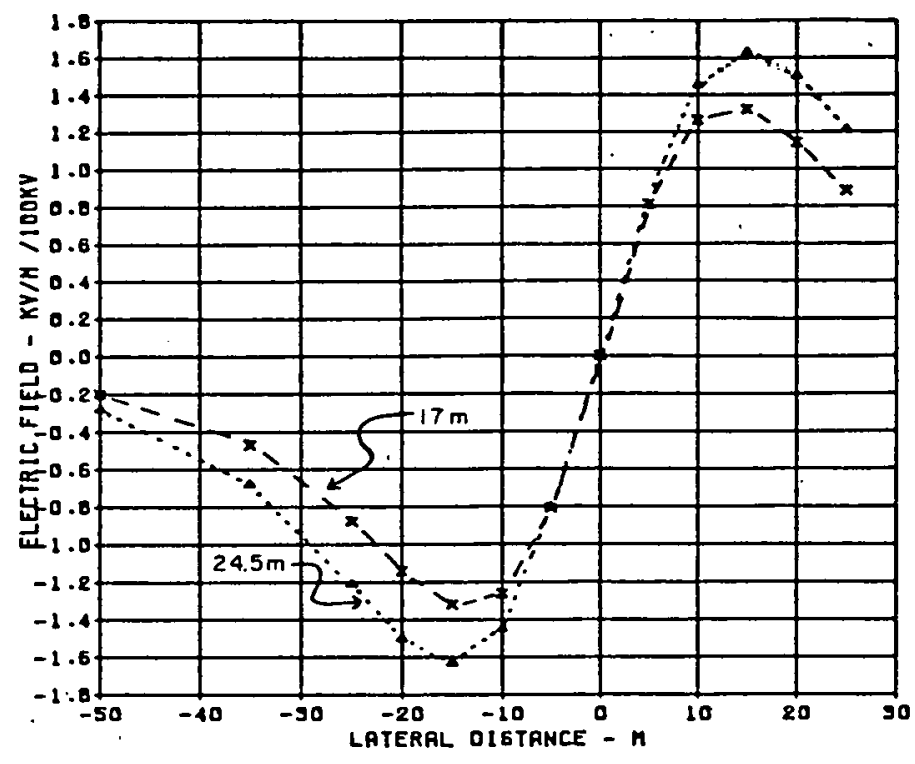

Fig. 7 Calculated Electrostatic Field Profiles 
Figures 8 and 9 are the field and ion current profiles for the two pole spacings with the line energized to $\pm 900 \mathrm{kV}$. The effect of pole spacing on line corona can easily be seen in Fig. 9. As indicated by the ground level ion currents, the negative pole has more corona activity for the case of a $17 \mathrm{~m}$ pole spacing than for a pole spacing of $24.5 \mathrm{~m}$. The positive pole shows little corona activity for either pole spacing. The effect on the electric field from the ion flow to ground is seen. in Fig. 8 where the field under the negative pole, with a pole spacing of $17 \mathrm{~m}$, exceeds the negative field for a $24.5 \mathrm{~m}$ pole spacing. This is the opposite of what is expected from a purely electrostatic consideration of the fields and is due to the fact that the negative pole is actively in corona for the $17 \mathrm{~m}$ pole spacing but has little corona activity and is not producing an ion flux to ground for a $24.5 \mathrm{~m}$ pole spacing.

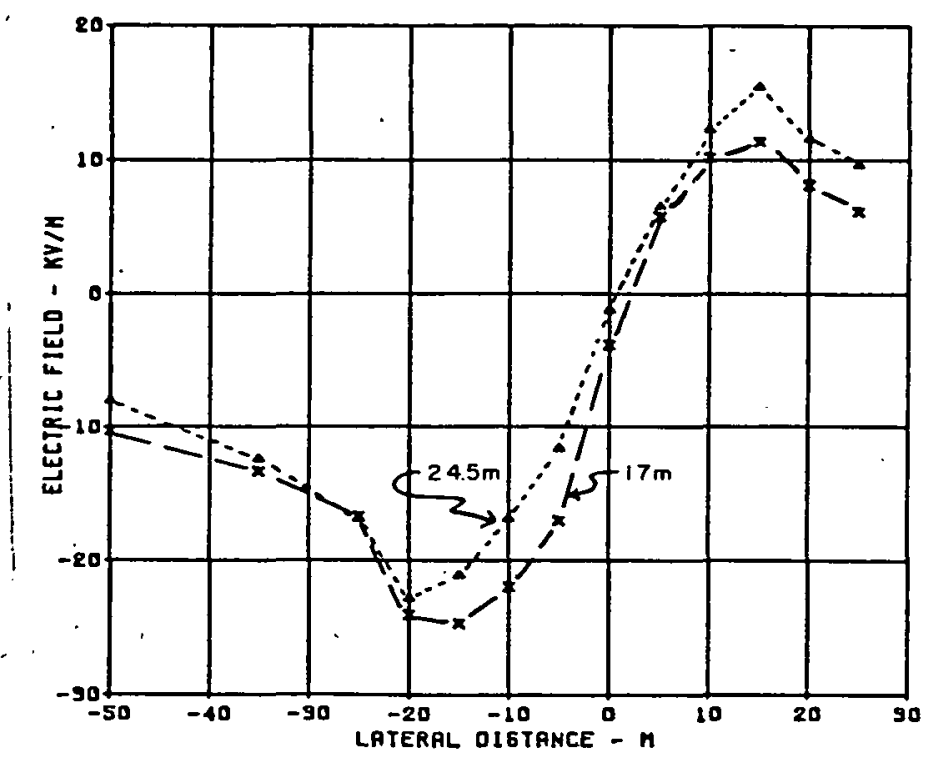

Fig. 8. Electric Field Profiles $\pm 900 \mathrm{kV}$

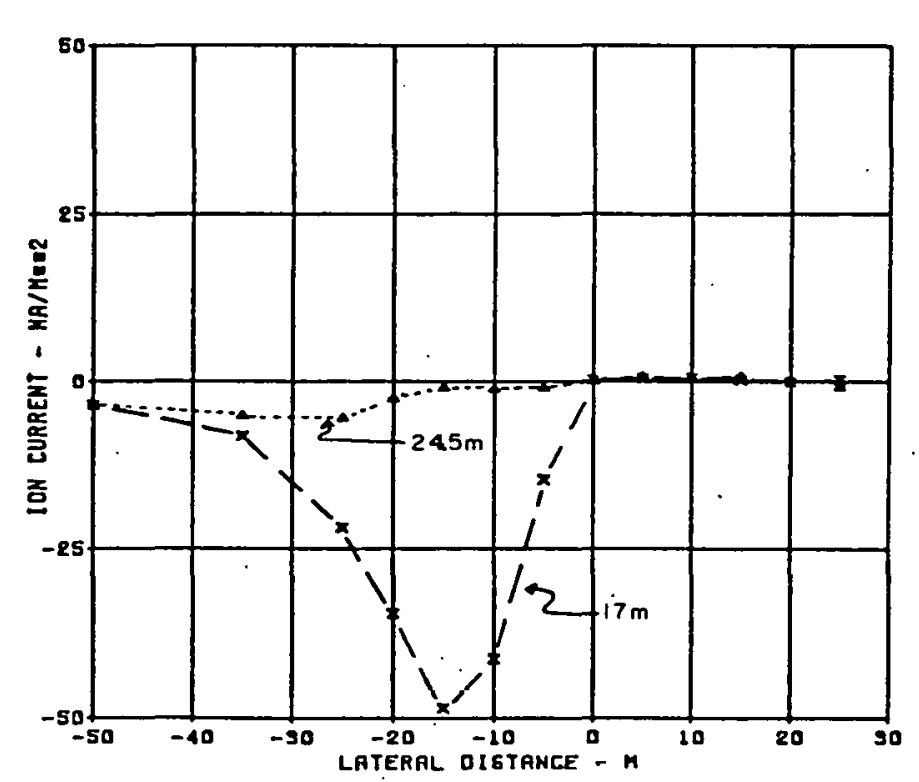

Fig. 9 Ion Current Profiles $\pm 900 \mathrm{kV}$ 
The field and ion current profiles at ground level for the line energized. at $\pm 1050 \mathrm{kV}$ are shown in Fig. 10 and Fig. 11. The negative and positive poles of the line have substantial corona activity for both the $17 \mathrm{~m}$ and $24.5 \mathrm{~m}$ pole spacings. Note that the fields produced by the $24.5 \mathrm{~m}$ pole spacing exceed those for the $17 \mathrm{~m}$ pole spacing.

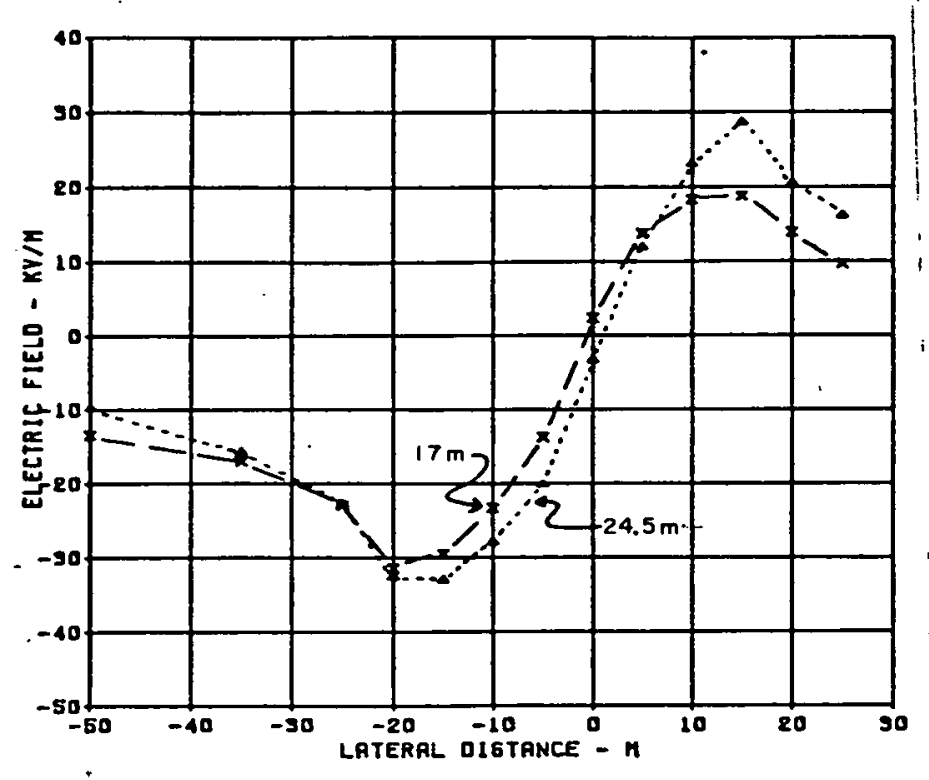

Fig. 10 Electric Field Profiles $\pm 1050 \mathrm{kV}$

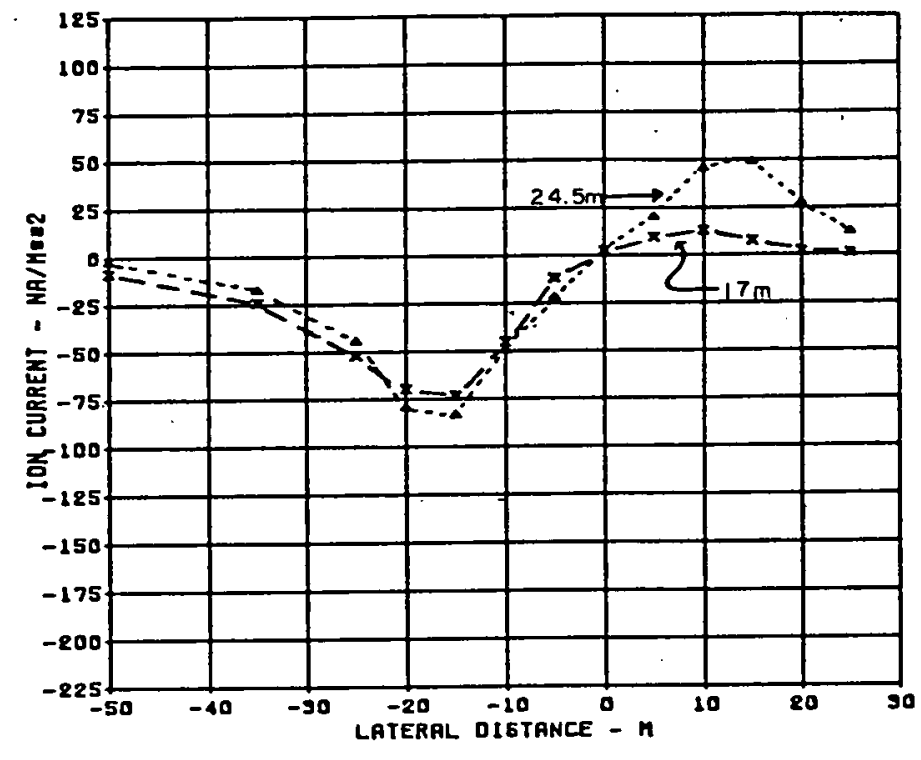

Fig. 11 Ion Current Profiles $\pm 1050 \mathrm{kV}$

Figure 12 and 13 are the field and ion current profiles with the line energized at $\pm 1200 \mathrm{kV}$. Both positive and negative poles now exhibit substantial corona activity and ion current densities are exceeding $100 \mathrm{nA} / \mathrm{m}^{2}$ at ground level.

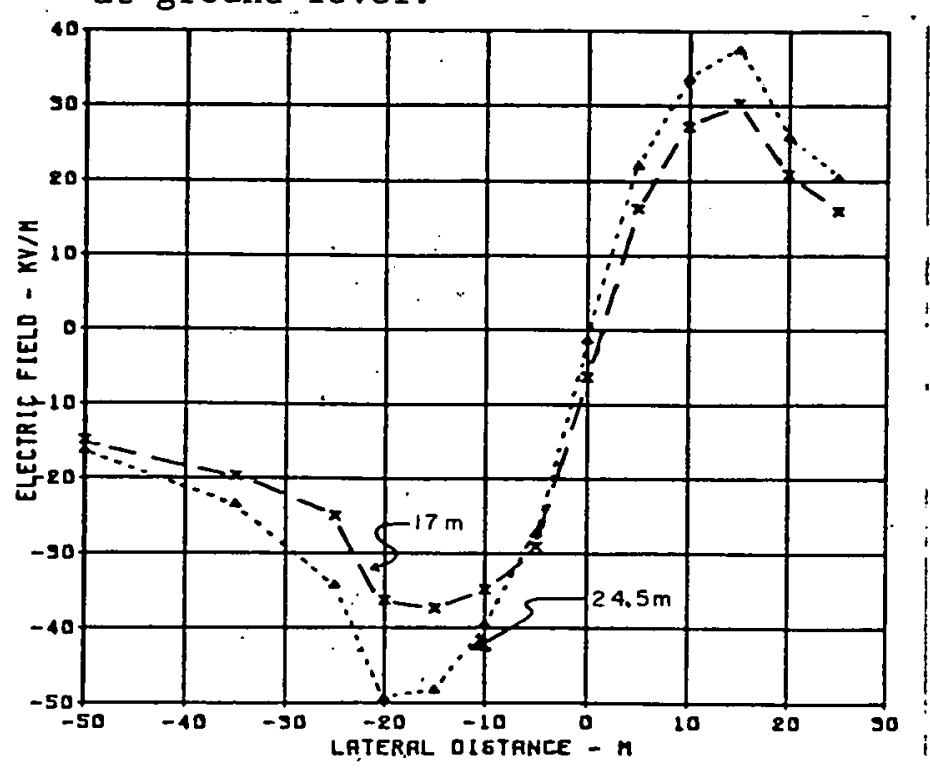

Fig. 12 Electric Field Profiles $\pm 1200 \mathrm{kV}$

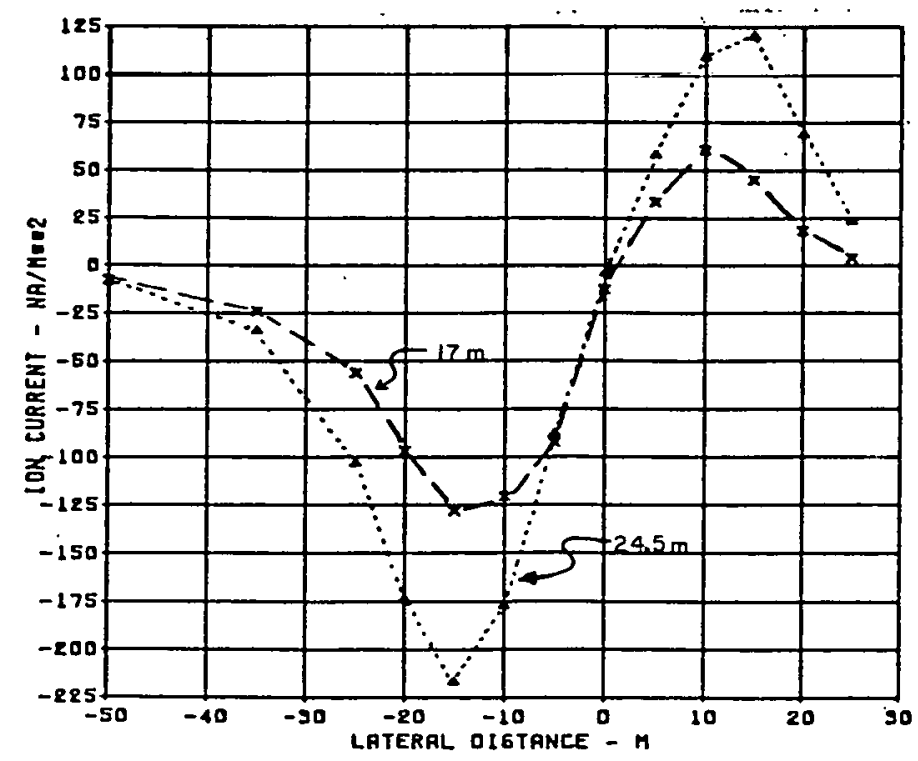

Fig. 13 Ion Current Profiles $\pm 1200 \mathrm{kV}$ 
The peak fields occur for the $24.5 \mathrm{~m}$ pole spacing. The peak negative electric field is $-50 \mathrm{kV} / \mathrm{m}$ and the peak positive electric field is $27 \mathrm{kV} / \mathrm{m}$. The asymmetry in the electric field profiles is most likely due to the differing amounts of field enhancement produced by the space charge from line corona. The amount of field enhancement is related to the differing amounts of positive and negative space charge flowing to ground which in turn depends on the corona onset voltage, for a positive or negative conductor, and the ion mobility.

\section{SUMMARY}

Due to the limited amount of data obtained thus far, the electric field and ion current profiles presented above should be viewed as only a preliminary indication of the conditions under a HVDC transmission line in fair weather. The data presented above was obtained from only a few days of line operation as a test of the instrumentation and data acquisition system.

No attempt was made to correlate the data to environmental factors such as relative humidity, wind speed, or atmospheric aerosol density. Correlation to environmental factors will be done when sufficient data has been collected.

\section{REFERENCES}

[1] Seventh Quarterly Report, DOE Contract EC-77-C-01-5059, December 1, 1978 - April 15, 1979.

[2] Fifth Quarter1y Report, DOE Contract EC-77-C-01-5059, June 1 - August 31, 1978.

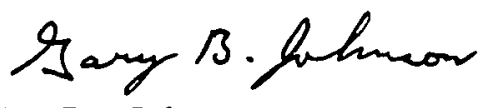

G. B. Johnson Research Engineer Project UHV 